TI 2011-014/1

Tinbergen Institute Discussion Paper

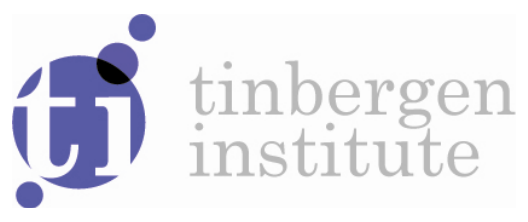

\title{
Nonrenewable Resources, Strategic Behavior and the Hotelling Rule: An Experiment
}

\author{
Roel van Veldhuizen \\ Joep Sonnemans
}


Tinbergen Institute is the graduate school and research institute in economics of Erasmus University Rotterdam, the University of Amsterdam and VU University Amsterdam.

More TI discussion papers can be downloaded at http://www.tinbergen.nl

Tinbergen Institute has two locations:

Tinbergen Institute Amsterdam

Gustav Mahlerplein 117

1082 MS Amsterdam

The Netherlands

Tel.: +31(0)205251600

Tinbergen Institute Rotterdam

Burg. Oudlaan 50

3062 PA Rotterdam

The Netherlands

Tel.: +31(0)10 4088900

Fax: +31(0)104089031

Duisenberg school of finance is a collaboration of the Dutch financial sector and universities, with the ambition to support innovative research and offer top quality academic education in core areas of finance.

DSF research papers can be downloaded at: http://www.dsf.nl/

Duisenberg school of finance

Gustav Mahlerplein 117

1082 MS Amsterdam

The Netherlands

Tel.: +31(0)20 5258579 


\title{
Nonrenewable Resources, Strategic Behavior and the Hotelling
}

\section{Rule: An Experiment*}

\author{
Roel van Veldhuizen ${ }^{\dagger}$ and Joep Sonnemans \\ CREED, University of Amsterdam and the Tinbergen Institute
}

January 20, 2011

\begin{abstract}
This study uses the methods of experimental economics to investigate possible causes for the failure of the Hotelling rule for nonrenewable resources. We argue that as long as resource stocks are high enough, producers may choose to (partially) ignore the dynamic component of their production decision, shifting production to the present and focusing more on strategic behavior. We experimentally vary stock size in a nonrenewable resource duopoly setting and find that producers with high stocks indeed pay significantly less attention to variables related to dynamic optimization, leading to a failure of the Hotelling rule.
\end{abstract}

Key Words: Experiments, Nonrenewable Resources, Dynamic Oligopoly

JEL Classification: C90, Q31, Q41, L13

${ }^{*}$ We would like to thank Thomas de Haan, Jona Linde, Arthur Schram, Jeroen van de Ven and Ailko van der Veen. We are also grateful to seminar participants at the University of Heidelberg, the University of Amsterdam, the Tinbergen Institute, the 2010 ESA World Meeting and the 2010 European Economic Review Talented Economists Clinic for their helpful comments. Financial support from the University of Amsterdam Research Priority Area in Behavioral Economics is gratefully acknowledged.

${ }^{\dagger}$ Corresponding author. E-mail: R.R.vanVeldhuizen@uva.nl 


\section{Introduction}

Today those who plan for the future prosperity of their nation realize the extent to which other raw materials are essential to the general well-being, and for some of these we can see no adequate substitutes. Foremost among these most useful and least abundant (...) commodities stands mineral oil. (...) [Even] the most optimistic American may well ask himself, Where will my children and children's children get the oil? - George Otis Smith, National Geographic (1920)

From the 19th century American gold rushes to the 21st century quest for drilling rights on the North Pole, there has always been something special about nonrenewable resources. Nonrenewable resources share the characteristic that they cannot be replenished, meaning that persistent use will eventually lead to physical or economic depletion (i.e. such that the remaining stock will not be worth extracting anymore). The nonrenewable resource family contains a broad variety of materials from oil and natural gas to iron and phosphate. Many nonrenewable resources have been an important part of our daily lives for so long that even in 1920 George Otis Smith deemed them "essential" (quote above; Smith, (1920)).

It is precisely because of the importance of these nonrenewable resources that politicians, geologists and companies alike have been concerned with resource depletion for a long time. Indeed, the words George Otis Smith wrote down some 90 years ago are surprisingly similar to comments made in recent years about coal depletion (e.g. Heinberg, 2007), phosphate depletion (e.g. Déry and Anderson, 2007) or oil depletion (e.g. Deffeyes, 2005). These concerns are rooted in the fear that if we continue to remain dependent on nonrenewable resources, we run the risk of economic (and military) collapse once these resources are no longer available. This has led to calls for governments to actively intervene and aid in the development of renewable alternatives. Indeed, former president Bill Clinton remarked in 2006 that "we may not have as much oil as we think, so we need to get in gear [and reduce oil dependence]" (Energy Bulletin, 2006), with then president George W. Bush going one step further by stating that the United States should "get off oil" (Mouawad, 2008).

Luckily, economic theory suggests that the situation may not be quite so bad. Hotelling 
(1931) showed that in a perfectly competitive industry, nonrenewable resource producers will deplete the resource at the socially optimal rate. Moreover, in the presence of market power (Solow, 1974) or the presence of a constant severance task (Heaps, 1985), the market will actually extract at a lower rate. To the extent that these factors are important, we should therefore be worried that nonrenewable resources will be exhausted too slowly. In theory, the ideological successors of George Otis Smith can thus relax knowing that depletion -when it occurs- is likely to occur at the socially optimal time or later, provided that Hotelling's framework holds.

Yet how confident can we be that nonrenewable resource producers actually follow the Hotelling approach? Hotelling showed that in a perfectly competitive environment with zero marginal costs and constant demand (real) prices should grow at the rate of interest -a result which has become known as the Hotelling rule. More generally, prices may in fact grow at a larger or smaller rate depending on the assumptions, yet they should always grow in the long run. ${ }^{1}$ How well, then, does Hotelling's framework fit the real world? Figure 1 gives a time series of crude oil prices since the 1860s. Clearly, there are occasional periods of increasing prices, yet real prices have overall remained around the same level despite an enormous increase in production (Adelman, 2002). Moreover, this pattern is by no means unique to oil prices; figure 2 shows that -like crude oil- copper, zinc and iron ore prices have also not reliably increased. More formally, in reviews of the empirical literature Krautkraemer (1998) and Livernois (2009) argue that support for the Hotelling framework is very limited.

Yet if the Hotelling framework is normatively the best way to approach the nonrenewable resource problem, what reason could nonrenewable resource owners have had for not adopting it? In this paper, we argue that the failure of the Hotelling rule may be the result of the multifacetedness of the nonrenewable resource problem. In particular, we argue that the nonrenewable resource problem consists of many different aspects (e.g. exploration, strategic behavior, technological developments, dynamic optimization etc.) and that in practice, pro-

\footnotetext{
${ }^{1}$ In the short run they may temporarily decrease under some assumptions, for example if extraction costs are positive and decreasing over time. However, prolonged stretches of non-increasing resource prices are implausible; see the next section for more details.
} 


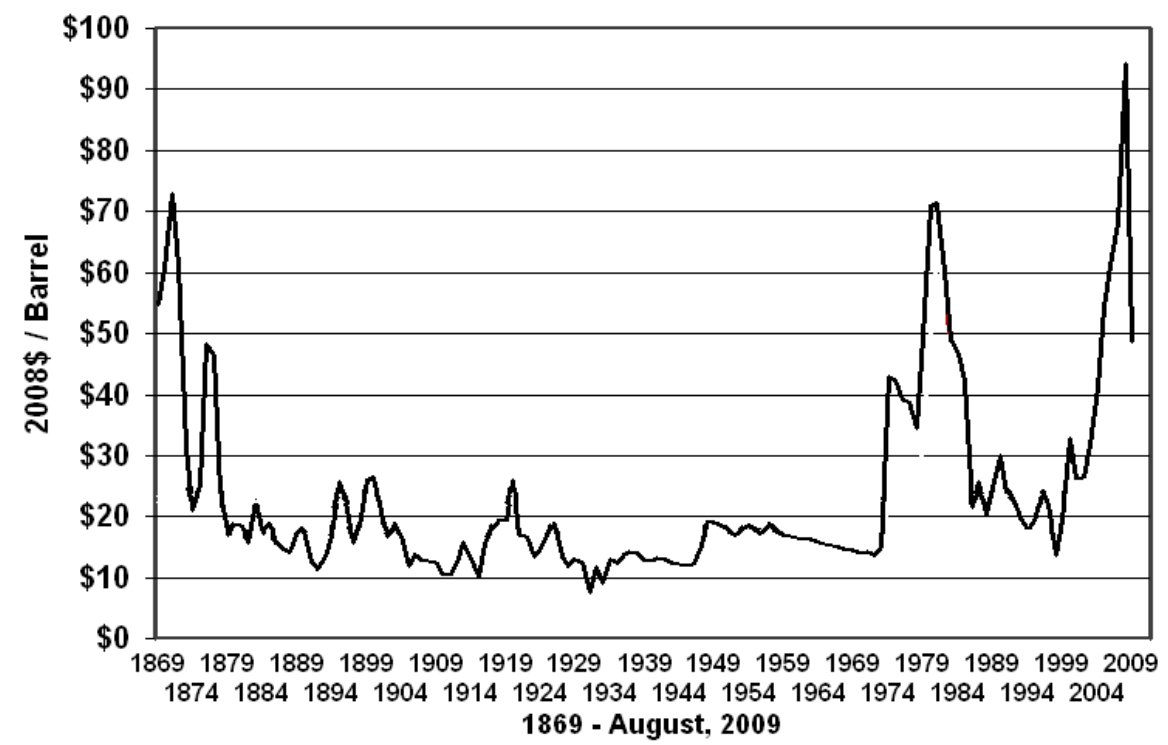

Figure 1: Crude Oil Prices (2008 dollars)

Note. This figure is adapted from "Oil Price History and Analysis (Updating)" by J.L. Williams, http://www.wtrg.com/prices.htm, 2009 (accessed April 22nd, 2010).

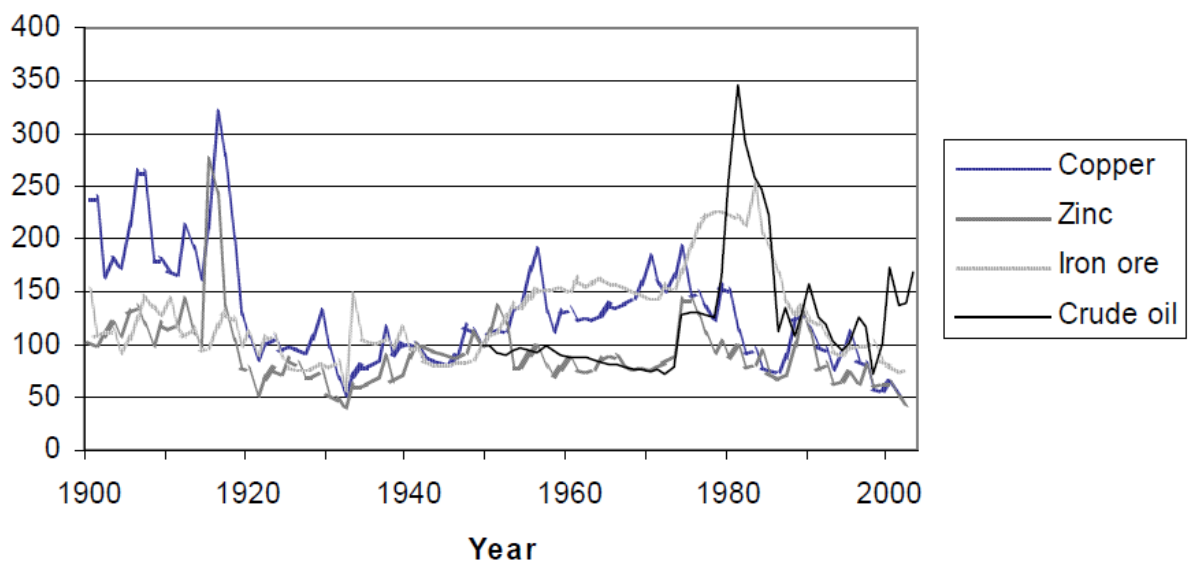

Figure 2: Resource prices (1949 dollars)

Note. This figure is reprinted from "Should We Worry About The Failure Of The Hotelling Rule" by T. Kronenberg, 2008, Journal of Economic Surveys, 22(4), 774-93. 
ducers may not be willing or able to take every aspect fully into account. Moreover we argue that the degree to which a nonrenewable resource producer pays attention to a given aspect of the resource problem depends on whether it can be feasibly included in the optimization problem, whether the benefits of including it outweigh the costs and whether the aspect is salient to the producer.

Indeed, we think that many nonrenewable resource owners may not have sufficient computational capacity to take every aspect into account for all future periods. Indeed, even including more than one aspect into a single model has proven very difficult. ${ }^{2}$ Moreover even if a nonrenewable resource producer did have the ability to include all aspects of the nonrenewable resource problem in its decision making process, it might not be beneficial for her to do so from a cost-benefit perspective. For example, making accurate predictions about market demand in 15 or 20 years is likely to be quite costly, whilst a transient change would have a negligible effect on present-day extraction rates. Moreover not all aspects of the nonrenewable resource problem may be equally salient to a producer. For example, the manager of a resource firm may not be directly concerned with long-run profits if she expects to retire long before the date of exhaustion has been reached. ${ }^{3}$

Thus, the degree to which a nonrenewable resource producer pays attention to a given aspect of the resource problem might depend on whether it can be feasibly included in the optimization problem, whether the benefits of including it outweigh the costs and whether the aspect is salient to the producer. Although in principle there are many possible aspects to consider, in this article we will focus on the two aspects that are in our opinion the most crucial parts of the nonrenewable resource problem. The first key aspect of the nonrenewable resource problem is that producers always have to take into account that their current extraction decision is going to affect future extraction possibilities. This is a necessary characteristic of the Hotelling framework and a necessary condition for the Hotelling rule to hold; we will refer to it as the dynamic optimization aspect. The less attention producers pay

\footnotetext{
${ }^{2}$ See e.g. Groot, Withagen, and de Zeeuw (2003) for a discussion of some of the difficulties associated with incorporating both dynamic optimization and strategic behavior into a single model.

${ }^{3}$ Pindyck (1981) and Farrow (1985) give evidence that resource firms may ignore some aspects of the resource problem in practice. Cairns (1986) gives an example of how mining firms may ignore the dynamic optimization aspect in the Nickel industry.
} 
to the dynamic optimization aspect, the further away from the optimal Hotelling rule their production path will be. The other key element of most real-life incarnations of the nonrenewable resource problem is that multiple producers are active on the market, leading to the possibility of strategic behavior with respect to other producers. Though strategic behavior may not be present on all nonrenewable resource markets, it is still an element of great economic interest, as evidenced by the large number of papers focusing on this topic (see Newbery, 1981; Lewis and Schmalensee, 1980; Groot, Withagen, and de Zeeuw, 2003; Loury, 1986; Smith, 2005 among others). The less attention producers pay to the strategic behavior aspect, the less they update their production decision on the basis of the production decision of other producers. The Hotelling rule will hold approximately in cases where producers focus primarily on dynamic optimization and will fail in cases where producers focus mostly on strategic behavior.

Moreover we argue that the degree to which a nonrenewable resource producer pays attention to a given aspect of the resource problem depends on the size or longevity of her resource stock. In particular, the higher the resource stock is, the less (more) attention a producer will pay to dynamic optimization (strategic behavior). Indeed, for a high stock producer the date of exhaustion is still far in the future, which may make it computationally difficult to stick to a dynamically optimal time path for all periods, whereas the benefits of doing so may not outweigh the costs in any case. Moreover, neither she nor her stockholders or head of state may be particularly interested in getting a dynamically optimal production path; present profits may be much more salient. On the other hand, it will be relatively profitable to behave strategically with respect to other producers and perhaps even create a cooperative agreement (e.g. OPEC). Similarly, the date of exhaustion for a small stock producer is more imminent, making it more beneficial, computationally easier and more salient to take the imminent exhaustion into account. Since most nonrenewable resource producers in practice still have a large remaining stock (Zwanenburg, 2010), we should thus expect them to focus more on strategic behavior than on dynamic optimization, leading to a failure of the Hotelling rule.

Ideally, it would be possible to investigate the relationship between stock size and the 
applicability of the Hotelling framework using field data. However, using field data to investigate this relationship might be problematic for several reasons. One problem is that field data may be biased (a well-known example is OPEC 'proven reserve' data). ${ }^{4}$ Field data may also be unavailable altogether (esp. marginal cost data; Krautkraemer, 1998) or may simply be very noisy (e.g. because of unobserved demand shifts, small changes in technology etc., see e.g. Griffin, 1985). Moreover, even if good data are available, it may be hard to compare high stock and low stock producers, since they are likely to differ on more than just the stock dimension. ${ }^{5}$ Also, any observed production differences may be the result of changes in factors outside the model of interest (such as government interventions, oil booms on the stock market, see e.g. Hamilton, 2009) which might not be extractable from the data or otherwise may not be easily incorporated into a dynamic model. Moreover, even for well-funded optimally behaving producers, output changes may still be the result of revised expectations, which are also rarely available from field data.

These data concerns can, however, be addressed using laboratory experiments. In a controlled laboratory environment, it is possible to exclude factors outside the model as well as possible biases or noise by keeping the environment fixed between sessions. Expectations can also be obtained, such that revised expectations can be taken into account and be disentangled from strategic concerns. Indeed, the field of experimental economics has a large tradition of experiments in oligopoly (see for example Huck, Normann, and Oechssler (1999, 2000); Abbink and Brandts (2008, 2009) or see Engel (2010) for an overview of the literature). To our knowledge, this is the first study to investigate producer behavior in a nonrenewable resource oligopoly in an experimental setting.

We run an experiment in which two producers with a limited stock of nonrenewable resources are paired on a nonrenewable resource Cournot market. Thus, the experimental setting allows for strategic behavior and dynamic optimization whilst abstracting away from

\footnotetext{
${ }^{4}$ In particular, since OPEC production quotas became based on proven reserves in the early 1980s, the official estimates of some OPEC states (including Saudi Arabia, UAE, Iran and Iraq) have shown suspiciously large upward jumps in reserve levels. For example, the UAE's proven reserve increased by nearly $200 \%$ from 1985 to 1986 (BP, 2010). See Gerlagh and Liski (Forthcoming) for a reason why it may be optimal to overstate reserves.

${ }^{5}$ Also, low stock nonrenewable resource markets are quite hard to find, since in most cases resource pools are still projected to be sufficient for several decades (Zwanenburg, 2010).
} 
other aspects. We experimentally vary stock size and find that producers with low stocks pay significantly more attention to variables related to dynamic optimization. Moreover, evidence also seems to suggest that producers with high stocks pay more attention to variables related to strategic behavior. This pattern is reflected by market outcomes as well: in the high stock treatment extraction rates are persistently above the Nash level, whereas in the low stock treatment they are never higher than the Nash level in any period. As a consequence, prices are persistently too low in the high stock treatment, whereas they are roughly dynamically optimal in the low stock treatment.

In the next section, we will review Hotelling's work as well as several previous attempts at explaining the failure of the Hotelling rule. In section 3 we formulate the model that forms the basis of the experiment, which brings us to the hypotheses for the experiment in section 4. In section 5, we then go over the design of the experiment before we show the results in section 6. Finally, section 7 concludes.

\section{Literature Review}

The origins of the field of nonrenewable resource economics can be traced back to Harold Hotelling (1931). In the spirit of an earlier work by Gray (1914), Hotelling sets out the problem of a firm -in his case the owner of a mine ${ }^{6}$ - facing a limited stock of resources. Hotelling's work is notable for its novelty and for its sheer scope: it addresses not just a then new economic problem but also discusses many relevant extensions, including uncertainty, the possibility of exploration and market power. It has consequently been the starting point for most papers in the field and will also be the starting point of this article, which is why we will briefly go into its main findings. ${ }^{7}$

Hotelling starts his analysis by examining the problem of a resource-constrained firm in a fully competitive market. Firms in a competitive market face a trade-off between extracting their resource now and extracting it at some future date. For the market to be in equilibrium and to prevent arbitrage opportunities, firms have to be indifferent about when to extract

\footnotetext{
${ }^{6}$ In this article, we shall use the terms firms, producers and resource owners interchangeably.

${ }^{7}$ See Devarajan and Fisher, 1981 for an early overview of the impact of Hotelling's work on the field.
} 
their resource. Hotelling shows that in a competitive environment with zero marginal costs, the only way to keep resource owners indifferent between extracting now and extracting in the future is for resource prices to grow at the rate of interest. That way, extracting a marginal unit in the present period will mean a loss of today's price plus the interest over today's price, and this will be equal to the benefit of extracting a marginal unit in the future. This result has become known as the Hotelling rule.

The Hotelling rule in its original form is valid only in a competitive environment with zero marginal costs. However, it can be generalized to other environments as well. In a more general form, the Hotelling rule states that the scarcity rent should grow at the rate of interest. The scarcity rent represents the excess return that producers get to compensate them for exhausting their resource. The scarcity rent is thus equal to the difference between the equilibrium price on a nonrenewable resource market and the equilibrium price on the same market if the resource had been abundant. It is also sometimes referred to as the in situ value, (marginal) user cost or shadow price of the resource. Examples of generalized Hotelling rules are presented in studies which allow for exploration possibilities or technical innovation (Pindyck, 1978, 1980; Arrow and Chang, 1978), allow producers to have non-profit maximizing motives (Mead, 1979) and allow the market to be less than fully competitive (Newbery, 1981; Loury, 1986; Polasky, 1992; Groot, Withagen, and de Zeeuw, 2003).

Many of these generalizations were created to try to explain the failure of the original Hotelling (1931) rule. It is possible for a generalized Hotelling rule to imply non-increasing prices under certain conditions. Intuitively, in any Hotelling-type model prices are pushed upwards over time by increasing scarcity rents. For a model to be consistent with nonincreasing prices, there thus needs to be an alternative force that provides enough downward pressure on prices to compensate the upward pressure caused by the increasing scarcity rents. In the following paragraphs, we will briefly review several important ways by which nonincreasing prices can occur.

Firstly, including exploration possibilities can lead to a U-shaped price pattern if there are stock effects in the cost function (Pindyck, 1978). That is, newly found resource stocks may be cheaper to extract, which means that marginal costs may more than match increasing 
scarcity concerns, leading to decreasing prices. Relatedly, technological developments can also lead to decreasing marginal costs and (non-increasing or) decreasing price patterns in the short to medium run (Slade, 1982). In both cases price decreases are the result of marginal costs decreases which more than match scarcity rent increases. However, since marginal costs are bounded from below, prices will eventually have to start rising. Thus, either exploration possibilities or technological developments can only explain non-increasing resource prices in the short run; in the long run they imply a U-shaped price pattern. However, there is little evidence for a long-run U-shaped price pattern for any nonrenewable resource. ${ }^{8}$

It is also possible for non-increasing prices to occur for strategic reasons. For example, if price is taken as a signal of resource abundance, it may be beneficial for resource owners to keep prices artificially low to prevent a third party from developing a renewable alternative as in Gerlagh and Liski (Forthcoming). However, their model with discounting predicts increasing prices in the short run and falling prices in the long run, which is inconsistent with price data. Alternatively, non-increasing prices can also be caused by insecure property rights. This applies for example to the early history of American oil drilling, when property rights applied to land parcels and not oil fields, meaning that there were often multiple pumpjacks extracting oil from the same field. ${ }^{9}$ More recently, it also applied to the Middle East oil fields of the 1960s and 1970s, when the big American oil firms correctly anticipated that their resources would be confiscated in the near future (e.g. Mead, 1979). The main problem with a property rights explanation is that property rights have actually been quite well defined for other resources and other time periods and there, too, prices have rarely consistently increased.

There are several more extensions of the Hotelling set-up which allow prices to be nonincreasing in the short run, including capacity constraints and stochastic exploration (see Krautkraemer (1998)'s or Livernois (2009) survey of the literature for more details). They could therefore explain the empirically observed pattern of non-increasing resource prices.

\footnotetext{
${ }^{8}$ A notable exception is formed by oil prices from 1870 to 1978. Indeed Slade (1982) finds a U-shaped time pattern for this time period. However, prices have since fallen back to World War II levels and then risen again. Thus her results may no longer be applicable if price data are extended beyond the 1970s.

${ }^{9}$ This led Smith (1920) to lament "the waste of capital and labor under conditions of competitive drilling".
} 
At the same time, scarcity rents should still be increasing. ${ }^{10}$ However, studies examining scarcity rent data have failed to consistently reveal increasing trends (Farrow, 1985; Halvorsen and Smith, 1991; Cairns and Davis, 1998). For example, Farrow (1985) gives a case where scarcity rents actually seem to decrease over time.

What all these extensions have in common is that they attempt to reverse the implications of the basic Hotelling rule (i.e. find a model that predicts decreasing prices instead of increasing prices) while keeping the main assumption -firms dynamically optimize profits over a long time horizon- intact. However, following Pindyck (1981) and Cairns (1986) in the next sections we argue that in fact the assumption that firms dynamically optimize profits over a long time horizon -though normatively appealing- may not be descriptively accurate. Indeed, as Adelman (2002) and Hamilton (2009) argue, another way to interpret historical data on oil prices is to say that "oil prices historically hav[e] been influenced little or none at all by the issue of exhaustability" (Hamilton, 2009). This line of reasoning is consistent with non-increasing resource prices; it is also consistent with anecdotal and empirical evidence suggesting that simple heuristics (mining practice) may provide a better description of actual behavior (see Farrow, 1985; Cairns, 1986). We will come back to this idea in section IV. First, however, we will derive the Hotelling Cournot oligopoly model that forms the benchmark for the remainder of the article.

\section{Theoretical Framework}

We generalize the Hotelling set-up by allowing for market power in the Cournot sense along the lines of Loury (1986) and Polasky (1992). The resulting model is somewhat more general than the original Hotelling framework; it includes monopoly and perfect competition as limiting cases. ${ }^{11}$ Importantly, the model allows for both strategic behavior and dynamic optimization. Other than allowing for market power, we stick to the original Hotelling set-up as much as

\footnotetext{
${ }^{10}$ An important exception to this point is formed by stock degradation effects. Indeed, if extraction costs increase sufficiently strongly as the resource stock gets depleted, it is possible for scarcity rents to decrease over time, whilst prices would then be increasing (Livernois and Martin, 2001). However, this pattern would then be inconsistent with the empirically observed pattern of non-increasing prices.

${ }^{11}$ Of the alternative market structures commonly used with non-renewable resource markets, only the Cartelversus-Fringe set-up cannot be captured by the model.
} 
possible. Hence, we abstract away from possibilities of exploration, capital investments et cetera.

Let there thus be $N$ symmetric producers indexed $i$ with a per-period profit function $\Pi\left(q_{t}^{i}, Q_{t}\right)$ that depends on the producer's quantity of the resource sold in period $t\left(q_{t}^{i}\right)$ as well as the market quantity sold in period $t\left(Q_{t}=\sum_{i=1}^{N} q_{t}^{i}\right)$. Moreover, each producer $i$ faces a resource constraint which limits total production over all periods to be no larger than an initial private resource stock $S_{0}^{i}$. There is a (constant) common discount factor $\delta$ which is equal to $\frac{1}{1+r}$, where $r$ is the market interest rate. Moreover, let $0<T \leq \infty$ be the maximum number of periods. The producer's problem is then to solve the following maximization problem with respect to $q_{t}^{i}$ :

$$
\begin{array}{r}
\max \sum_{t=0}^{T} \delta^{t} \Pi\left(q_{t}^{i}, Q_{t}\right) \\
\text { subject to } \sum_{t=0}^{T} q_{t}^{i} \leq S_{0}^{i}
\end{array}
$$

To keep the experiment as simple as possible for participants, we adopt a linear demand framework with $a$ the choke price and $b$ the slope of the demand function. We also assume that marginal costs are constant and (without further loss of generality) equal to zero. Assuming an open-loop strategy space in the spirit of Loury (1986), this yields the following Lagrangian:

$$
L=\sum_{t=0}^{T} \delta^{t}\left(a-b Q_{t}\right) q_{t}^{i}-\lambda^{i}\left(\sum_{t=0}^{T} q_{t}^{i}-S_{0}^{i}\right)
$$

The solution to this Lagrangian depends on the assumptions that the producer makes about the market quantity $Q_{t}$. Offerman, Potters and Sonnemans (2002) mention three benchmarks, which differ only in the degree to which individual producers think they can influence the market quantity $Q_{t}$. For the Nash equilibrium benchmark, producers assume that they can only influence their own quantity; they treat the production plans of other producers as given. Imposing symmetry on the other producers for the moment, the market 
quantity becomes $Q_{t}=(N-1) q_{t}^{n}+q_{t}^{i}$, where $q_{t}^{n}$ is the average quantity produced by the other producers. In the second benchmark -Collusion- producers maximize joint profits; in the symmetric case this is equivalent to maximizing profits while assuming that all other producers adopt the same production schedule. The market quantity then becomes $Q_{t}=N q_{t}^{i}$. Finally, for the Walras (or competitive) benchmark, producers (mistakenly) believe that their production decision has no influence on the market price and hence the market quantity (i.e. producers assume that $\left.Q_{t} \perp q_{t}^{i}\right)$. Moreover, let us define the average quantity on the Walrasian market $q_{t}^{w}$ such that $Q_{t}=N q_{t}^{w}$ (note that producers assume $q_{t}^{w} \perp q_{t}^{i}$ as well). Plugging the three expressions for $Q_{t}$ into the Lagrangian, taking the derivative with respect to $q_{t}^{i}$ and $q_{0}^{i}$, and then by symmetry putting $q_{t}^{i}=q_{t}^{w}$ for the Walras benchmark and $q_{t}^{i}=q_{t}^{n}$ for the Nash benchmark yields the following expression:

$$
q_{t}^{i} \geq q_{U}-\frac{q_{U}-q_{0}^{i}}{\delta^{t}} \text { with } q_{U}^{n}=\frac{a}{(N+1) b}, q_{U}^{c}=\frac{a}{2 N b} \text { and } q_{U}^{w}=\frac{a}{N b}
$$

This is the Hotelling rule for symmetric oligopolies expressed in terms of quantities. Here, $q_{U}$ is the unconstrained or static benchmark quantity, which differs depending on the benchmark that is adopted; it is equal to the quantity that would be produced in the absence of resource scarcity. By summing over all firms, equation 1 can also be rewritten in terms of prices:

$$
p_{t}^{i} \leq p_{U}+\frac{p_{0}-p_{U}}{\delta^{t}} \text { with } p_{U}^{n}=\frac{a}{N+1}, p_{U}^{c}=\frac{a}{2} \text { and } p_{U}^{w}=0
$$

The first term on the right of equation 2 is the unconstrained benchmark price. The difference between the actual market price and the unconstrained market price is made up by the second term on the right $\left(\frac{p_{0}-p_{U}}{\delta^{t}}\right)$ which is the scarcity rent of the resource. This term is positive and exponentially increasing; as a result prices will increase exponentially with respect to the unconstrained benchmark. Note that since $p_{U}^{w}<p_{U}^{n}<p_{U}^{c}$ for $N>1$, prices are increasing at the highest rate in the Walras benchmark and at the lowest rate in the Collusive benchmark. This implies that $p_{0}$ is lowest for the Walras benchmark and highest 
for the Collusive benchmark. ${ }^{12}$ Finally, note that equations 1 and 2 hold with equality for all periods with positive production levels.

These three adapted Hotelling rules describe part of the optimal benchmark solutions. The two remaining steps are to use the resource constraint to find the optimal $q_{0}$ (or equivalently $\left.p_{0}\right)$ and the optimal time of exhaustion $t^{*}$. This procedure, though mathematically straightforward, is somewhat tedious and thus omitted. Figure 3 shows the benchmark price and quantity levels for one of the parameter combinations used in the experiment. ${ }^{13}$

For all three benchmarks, there is only one symmetric set of quantities satisfying equation 1 (and hence equation 2). To see this, note first that to prevent arbitrage equation 1 must hold with equality in all periods where production is positive. Note next that the resource constraint $\sum_{0}^{T} q_{t}^{i} \leq S_{0}^{i}$ will be binding as long as the resource is not abundant (i.e. as long as $\left.S_{0}<T q_{U}\right)$. Now take any two positive quantities $q^{\prime}$ and $q^{\prime \prime}$ in any period $\tau$ where $q_{\tau}^{\prime \prime}>q_{\tau}^{\prime}$. By equation 1, this implies $q_{t}^{\prime \prime} \geq q_{t}^{\prime}$ for all other $t>0$ as well. By the resource constraint we get $\sum_{0}^{T} q_{t}^{\prime}=S_{0}$ which implies $\sum_{0}^{T} q_{t}^{\prime \prime}>S_{0}$, which is not possible. Similarly, $\sum_{0}^{T} q_{t}^{\prime \prime}=S_{0}$ implies $\sum_{0}^{T} q_{t}^{\prime}<S_{0}$, which cannot be optimal as long as the resource is not abundant. Thus there can be only one symmetric set of quantities satisfying equation 1 for each benchmark.

For the Nash equilibrium, it is in fact possible to show that the the symmetric equilibrium is the only possible equilibrium. For this purpose, we need to show that no asymmetric equilibria can exist. To do this we first rederive equation 1 without imposing symmetry. For any period where production is positive, we get:

$$
q_{t}^{i}=q_{U}^{m}-\frac{q_{U}^{m}-q_{0}^{i}}{\delta^{t}}-\frac{1}{2}\left[\sum_{j \neq i} q_{t}^{j}-\sum_{j \neq i} \frac{q_{0}^{j}}{\delta^{t}}\right]
$$

Here, $q_{U}^{m}=\frac{a}{2 b}$ is the unconstrained monopoly quantity. If we take any two producers $k$ and

\footnotetext{
${ }^{12}$ Since high prices and low production levels go together, collusion actually leads to slower extraction and greater conservation of the resource. This point was also noted by Solow, 1974, who argued that "if a conservationist is someone who would like to see resources conserved beyond the pace that competition would adopt, then the monopolist is the conservationists friend. No doubt they would both be surprised to know it." (Solow, 1974, p. 5)

${ }^{13}$ In fact, these are the parameters of treatment HIGH as in table 1, see section five.
} 

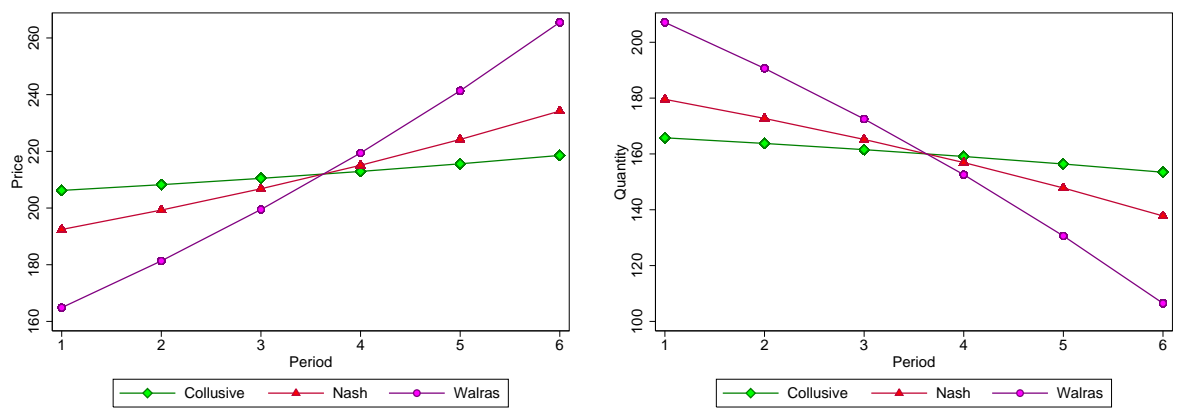

Figure 3: Benchmark Prices and Quantities

Note. This figure plots the symmetric benchmark market prices and quantities for treatment HIGH of the experiment as a function of time.

$l$ and subtract the expressions for $q_{t}^{k}$ and $q_{t}^{l}$ from each other we get:

$$
q_{t}^{k}-q_{t}^{l}=\frac{q_{0}^{k}-q_{0}^{l}}{\delta^{t}}
$$

Now suppose that $q_{0}^{k}>q_{0}^{l}$. By the previous equation, this implies that $q_{t}^{k}>q_{t}^{l}$ for all $t>0$ as well. Yet by the resource constraint we know that $\sum_{0}^{T} q_{t}^{k}=S_{0}$ which implies $\sum_{0}^{T} q_{t}^{j}>S_{0}$, which violates the resource constraint. Indeed, the only way for both resource constraints to hold with equality is if $q_{t}^{k}=q_{t}^{l}$ for all $t$. As a consequence, any Nash equilibrium needs to be symmetric; it follows that the Nash equilibrium of equation 1 is unique.

The Collusive and Walras benchmark quantities are unique at the market level. However, within a market a continuum of alternative benchmarks also exists where the market quantity is equal to the market quantity of the symmetric benchmark in every period but production levels are asymmetrically distributed across producers. Intuitively, the reason for this is that the optimal strategy for Collusive or Walras producers depends only on market level variables -market prices and market profit levels respectively.

\section{Hypotheses}

In previous sections we saw that the Hotelling rule does not seem to describe the data very well. In this paper, we argue that the failure of the Hotelling rule may be the result of the 
multifacetedness of the Hotelling framework. Indeed the nonrenewable resource problem is a mixture of several aspects, including for example exploration, strategic behavior, technological developments, dynamic optimization etc. Moreover, we argue that resource owners do not always take every aspect fully into account in their decision making process. In this section, we will examine this line of reasoning in greater detail and relate it to the hypotheses that are tested in the experiment.

One reason why producers do not take all aspects fully into account simultaneously is that doing so may be computationally impossible. Indeed, despite the enormous financial capabilities of some nonrenewable resource producers, even a very rich nonrenewable resource owner may not have a large enough computational capacity to take every aspect into account for all future periods. Pindyck (1981) argues that having a limited computational capacity may induce producers to (partially) ignore the dynamic consequences of their extraction decision. In general, including more than two aspects into a Hotelling framework may make the optimization problem intractable. Thus, resource owners have to make choices on what aspects of the decision problem they are going to focus their computational resources.

Secondly, even if a producer did have the ability to include every aspect of the nonrenewable resource problem in its decision making process, it might not be beneficial for her to do so from a cost-benefit perspective. For example, computing the dynamically optimal time path would require a knowledge of future demand elasticities. However, making accurate predictions about the elasticity of demand in 15 or 20 years is likely to be quite costly. An accurate prediction would for example require incorporating the expected availability of a backstop technology in the future, the expected sensitivity of consumers to environmental issues, expected population growth etc. At the same time, even a sizable change in the expected demand elasticity in 15 or 20 years may not affect the optimal current extraction rate very much. Indeed, for a resource stock that will not be depleted for many decades, even ignoring the resource constraint completely may not lead to a very different time path in the short run, since initial production levels may already be quite close to the unconstrained level. Thus, if fully incorporating certain aspects of the resource problem is costly and the benefits of doing so are small at least in the short run, then incorporating these aspects into 
the decision process may not be worth the costs.

Thirdly, not all aspects of the nonrenewable resource problem may be equally salient to a producer. For example, the manager of an oil firm with a substantial remaining resource pool -particularly one who expects to retire or move jobs in the not too distant future- may not be very mindful of finding a dynamically optimal production strategy. Indeed, doing so will be beneficial for the company in the long run only and may even reduce profits in the short run, which may have a negative effect on the manager's bonus payments. As Cairns (1986) and Slade (1988) have argued, this means that in practice the concerns of mining firms are likely to be dominated by price volatility, capital accumulation or cost control rather than dynamic optimization. Similarly, resource state companies might be under pressure from their government to acquire immediate income to finance public spending (see e.g. Ezzati, 1976; Teece, 1982; Griffin, 1985). Since the goal of increasing short term revenue is likely to be in direct conflict with maximizing long term profits, this will also lead the producer off the dynamically optimal path. ${ }^{14}$

Thus, the degree to which a nonrenewable resource producer pays attention to a given aspect of the resource problem depends on whether it can be feasibly included in the optimization problem, whether the benefits of including it outweigh the costs and whether the aspect is salient to the producer. In this article, we focus on what we have previously argued are two of the most important aspects of the nonrenewable resource problem: dynamic optimization and strategic behavior. ${ }^{15}$ Here, the dynamic optimization aspect refers to the ability to allocate resource sales over time in a dynamically efficient way, whereas the strategic behavior aspect refers to the ability to base a production decision on the expected production decision of other producers. Moreover, we propose that the degree to which producers focus on either dynamic optimization or strategic behavior is a function of the size of the remaining private resource pool. In particular, we argue that the higher the resource stock, the less

\footnotetext{
${ }^{14}$ An interesting example is provided by the island republic of Nauru. The surface of the island of Nauru consisted almost entirely of phosphate, a nonrenewable resource used to produce fertilizer. In the late 60s and early 70s, phosphate production had made Nauru so rich that as a country it actually had the highest GDP per capita in the world. However, its government used the proceeds to finance lavish public spending which eventually led to bankruptcy when the phosphate income started to fall in the 1990s (see e.g. Cox and Kennedy, 2005).

${ }^{15}$ Although the rest of the article will focus on these two aspects, we do believe that the subsequent analysis also extends to other aspects.
} 
(more) attention a producer will pay to dynamic optimization (strategic behavior).

We experimentally induced variation in stock size by running two treatments of a nonresource duopoly along the lines of the previous section. In treatment LOW, the unconstrained collusive quantity -which is the lowest of the three unconstrained benchmarks- could be maintained for only one period. In treatment HIGH, firms had a higher stock; as a result the unconstrained collusive benchmark could be maintained for up to five periods. Table 1 gives an overview of the parameters corresponding to the three treatments. ${ }^{16}$

We propose that the experimentally induced variation in stock size results in a shift of relative focus between strategic behavior and dynamic optimization. We assume that producers in both treatments are computationally constrained, so that they cannot fully take both aspects into account. Moreover, we assume that the dynamic optimization is both more salient and more cost-beneficial in treatment HIGH than in treatment LOW. ${ }^{17}$

To examine producer focus, we estimate the producers' production function by means of a panel regression. In terms of the estimated production function, we expect producers in treatment LOW to be pay more attention to two variables related to dynamic optimization. Firstly, producers who take dynamic optimization into account should -all other things being equal- extract a larger quantity of resources for higher levels of their resource stock. Similarly -conditional on the expected production level of the other producer- a producer will only take the other producer's stock into account if he is dynamically optimizing. Consequently, producers in treatment LOW should be most likely to condition their production decision on their remaining resource stock as well as the remaining resource stock of the other firm. This leads to the following hypothesis:

Hypothesis 1A: Producers in treatment LOW condition their production decision more strongly on their own stock and the stock of the other producer than producers in treatment HIGH.

\footnotetext{
${ }^{16}$ Besides stock there were two other parameters which differed between treatments. These were fixed costs and the conversion rate of experimental points to Euros. They were changed to create similar incentives in all treatments; they did not affect any of the benchmarks in any way.

${ }^{17}$ Relative to the static Nash level, producing according to the dynamic Nash level yields a $61 \%$ higher revenue for treatment LOW compared to a $48 \%$ higher revenue in treatment HIGH.
} 
For the strategic behavior aspect, a dual line of reasoning holds. In particular, the higher the resource stock, the more attention producers should pay to the strategic behavior aspect. Since producers can only behave strategically with respect to the other producer if they condition their decision on what they expect the other producer to do, a higher resource stock should increase the weight producers put on the expected quantity of the other producer. As a result, we expect firms in treatment HIGH to be more likely to base their production decision on what they expect the other firm to do than firms in the treatment LOW. This leads to the following hypothesis:

Hypothesis 1B: Producers in treatment HIGH condition their production decision more strongly on what they expect the other producer to produce than producers in treatment LOW.

If producers in treatment $\mathrm{HIGH}$ indeed focus less on the dynamic optimization aspect than producers in treatment LOW, this should also be visible in market production levels. In particular, a producer who pays no heed to the dynamic optimization aspect cannot produce according to a dynamic benchmark. Instead, the only available alternative is to produce according to an unconstrained or static benchmark, where the producer ignores the fact that current extraction will negatively affect future extraction possibilities. Since in both treatments any unconstrained benchmark has a higher extraction rate than any of the dynamic benchmarks, producers that adopt an unconstrained benchmark will push up production levels and consequently pull down prices and scarcity rents. Moreover, we saw that the Walras benchmark has higher extraction rates, lower prices and lower scarcity rents than either Nash or Collusion. This leads to the following hypothesis:

Hypothesis 2: Producers in treatment HIGH are closer to the Walras benchmark than producers in treatment LOW. 
Table 1: Experimental Time Line

\begin{tabular}{|c|c|c|c|c|}
\hline $\begin{array}{l}\text { Prologue 1: } \\
(35 \mathrm{~min})\end{array}$ & \multicolumn{3}{|c|}{$\begin{array}{l}\text { Nonrenewable Resource Monopoly } \\
\text { 1. Introduction \& Check up Questions } \\
\text { 2. Practice } \\
\text { 3. } 1 \text { Incentivized Round }\end{array}$} & \\
\hline $\begin{array}{l}\text { Prologue } 2 \text { : } \\
(30 \mathrm{~min})\end{array}$ & $\begin{array}{l}\text { Uncons } \\
\text { 1. Introduction } \\
\text { 2. } 3 \text { Incentivize }\end{array}$ & $\begin{array}{l}\text { ained Oligopoly } \\
\text { ¿ Check up Ques } \\
\text { Rounds }\end{array}$ & ions & \\
\hline $\begin{array}{l}\text { Main: } \\
\text { (65 } \min )\end{array}$ & $\begin{array}{l}\text { Nonrenewab } \\
\text { 1. Introduction } \\
\text { 2. } 10 \text { Incentiviz }\end{array}$ & $\begin{array}{l}\text { Resource Oligo } \\
\text { ¿ Check up Ques } \\
\text { Rounds }\end{array}$ & $\frac{\text { oly }}{\text { ions }}$ & \\
\hline & & rameters & & \\
\hline Stock & $\begin{array}{c}\text { PROLOGUE } 1 \\
280\end{array}$ & $\begin{array}{c}\text { PROLOGUE } 2 \\
\infty\end{array}$ & $\begin{array}{c}\text { LOW } \\
170\end{array}$ & $\begin{array}{c}\mathrm{HIGH} \\
480\end{array}$ \\
\hline$a$ & 372 & 360 & 372 & 372 \\
\hline$b$ & 2 & 1 & 1 & 1 \\
\hline Interest Rate & $10 \%$ & $10 \%$ & $10 \%$ & $10 \%$ \\
\hline Periods & 6 & 6 & 6 & 6 \\
\hline Producers & 1 & 2 & 2 & 2 \\
\hline
\end{tabular}

\section{Experimental Design}

The experiment was computerized using PhP/MySQL and consisted of two stages: the prologue and the main part (see table 1). We realized that the nonrenewable resource problem would initially be difficult for many participants to tackle. Since we did not want the Hotelling rule to fail because of a lack of understanding, we instituted a prologue that helped participants get to know the nonrenewable resource oligopoly problem in a stepwise way. The first phase of the prologue familiarized participants with the dynamic optimization aspect and the second phase familiarized them with strategic behavior. All in all, the prologue lasted for approximately 65 minutes. ${ }^{18}$. The prologue was identical for both treatments; treatment variation took place in the main part only. The main part consisted of a nonrenewable resource oligopoly; it will be the focus of the analysis in the next section. It lasted for approximately

\footnotetext{
${ }^{18}$ As a bonus, the prologue also allowed us to compare behavior in the prologue to behavior in the main part of the experiment.
} 
65 minutes as well, bringing the total duration of the experiment to 2 hours and 30 minutes including a questionnaire and payment.

The first phase of the prologue consisted of a nonrenewable resource monopoly. Participants first received a set of instructions and check-up questions (all instructions, questions and questionnaires are reprinted in appendix B). Once every participant had finished these, the experiment moved to a 15 minute practice stage, where each participant represented a resource owner with a limited stock of resources to be allocated over a total of 6 time periods (along the lines of the model of section 2 with $N=1$ ). Thus, participants were monopolists, which allowed them to learn about the the dynamic optimization aspect without having to worry about strategic behavior. In every time period, each participant decided how much of her resource to extract in the current period and how much to save for the remainder. After making a decision, the participant moved on to the next period where she again had to decide how much of her resource to extract. The decision problem became non-trivial because of discounting ${ }^{19}$; we incorporated discounting into the experiment by explicitly introducing an interest rate, such that income earned in earlier periods would be worth more at the end of the round..$^{20}$

After the sixth and final time period, participants were informed of their total income, which was calculated by adding profits and interest incomes from all periods and subtracting a fixed cost. Participants could then immediately proceed to the next practice round. During practice time every participant could go through as many practice rounds of the monopoly set-up as she liked. ${ }^{21}$ Thus, each participant had the time to check many possible production paths; as a result we expected most to get to know at least the basic rule of dynamic optimization in a nonrenewable resource context -which is to produce more in early periods than at the end. To make sure that every participant put in sufficient effort during practice, we also included a fully incentived round after practice. Including practice and check-up questions,

\footnotetext{
${ }^{19}$ Without discounting, all three benchmarks would collapse into extracting one sixth of the stock in every period.

${ }^{20} \mathrm{~A}$ possible alternative sometimes used in the literature is to use a stochastic ending mechanism, as is sometimes done. However, explicitly incorporating an interest rate avoids issues of risk aversion, the gambler's fallacy (see e.g. Terrel, 1994) and keeps all rounds comparable (same number of periods), whilst also staying close to the theoretical framework. In any case, Brown, Flinn, and Schotter (forthcoming) show that both mechanisms may yield very similar results.

${ }^{21}$ On average, participant went through 26 practice rounds, with a minimum of 10 and a maximum of 53.
} 
the first phase of the prologue took approximately 35 minutes.

The next phase of the prologue consisted of an unconstrained oligopoly. As a result, phase two allowed participants to familiarize themselves with the presence of another producer on the market (the strategic behavior aspect) without having to worry about dynamic optimization. In particular, we expected that phase two would teach participants at least the basic rule of Cournot oligopoly -which is that (up to a point) increasing production in a given period will increase your profits, but decrease the profits of the other producer on the market. Like phase one, phase two started off with a new set of instructions and questions. Participants then went through three rounds of the unconstrained oligopoly set-up; in every round participants were matched with one other participants, so that there were always two active producers on every market. Each round consisted of six periods as in the previous phase of the prologue; each market moved on to the next period once both producers had made their production decision. The experiment then moved forward towards the next round once all markets had finished all six periods; all three rounds contributed to final earnings. In total, phase two of the prologue lasted approximately 30 minutes.

After everyone had finished the prologue, the experiment moved on to the main part, which forms the basis for most of the analysis presented in the next section. All participants received a final set of instructions and questions and then went through ten incentivized rounds of the nonrenewable resource oligopoly framework of section 3. The main part thus incorporated both the dynamic optimization aspect and the strategic behavior aspect. Each participant once again represented a resource owner with a limited stock of resources as in the first phase of the prologue; moreover participants were paired so that there were always two active producers on every experimental market (as in the second phase of the prologue). During the decision process the decision screen gave participants access to the production decisions of both participants as well as the price levels in preceding periods and remaining resource stocks. ${ }^{22}$ After the sixth and final time period, participants were informed of their total income, which was calculated by adding profits and interest incomes from all periods and subtracting a fixed cost. Once all other groups were done as well, the experiment moved

\footnotetext{
${ }^{22}$ An example of a decision screen is given at the end of Appendix B.
} 
on to the next round, where the same set-up was repeated. ${ }^{23}$ In total, there were ten rounds, each of which was incentivized.

In general, we realized that even after having familiarized participants with both aspects of the nonrenewable resource problem in the prologue, the problem would still be hard for many of them for a large time horizon or a large number of competitors. Hence, we stuck to a relatively simple set-up by limiting the number of periods to six and group size to two. ${ }^{24}$ Moreover, all participants had access to an on-screen calculator which allowed them to compute the profits and interest incomes for any period and any production level of themselves and the other producer.

One final thing to note about the main part is that in every period of every even round participants were asked to indicate how much they expected the other firm to produce in that period. Any strategic production decision directly depends on the expected production strategy of other producers; a big advantage of experiments is that expectations can be elicited directly. ${ }^{25}$ At the end of the experiment one expectation was randomly picked to be paid out. For this purpose, we asked one randomly determined subject to come forward and roll a die to determine the round and period that would be paid out. The pay-off was determined using a linear scoring rule, where a unit deviation from the actual value would reduce earnings by 20 cents, from a maximum of five to a minimum of zero Euros.

After finishing the last round of the main part, participants received an overview of their earnings over the whole experiment. They were then asked to fill out a questionnaire, which consisted of some background questions, some questions relating to the way they played in the experiment as well as the shortened version of the Stanford Time Perspective Inventory (D'Alessio et al., 2003) -a questionnaire related to time preferences.

\footnotetext{
${ }^{23}$ In every round, participants were matched to a different participant in their matching group (which was between 6 and 10 participants in size, depending on the number of participants in the session). Thus, participants could never face the same person twice in succession. Moreover participants never learned the identity of the other participant.

${ }^{24}$ Indeed, we had previously run a pilot (Veldhuizen, 2009) where we had 10 periods and a group size of three and found that a small number of participants occasionally took a very long time (sometimes nearly 10 minutes) to make a single production decision. Since $98 \%$ of all decisions in the pilot were made within 90 seconds, we decided to limit the decision time per period to two minutes.

${ }^{25}$ However, elicited expectations are not uncontroversial in the literature. In particular, they might suffer from a false consensus or reciprocity effect (see e.g. Croson, 2000) and even the elicitation procedure itself may change behavior in a round (see e.g. Gächter and Renner, 2010). We come back to this issue in appendix A.
} 

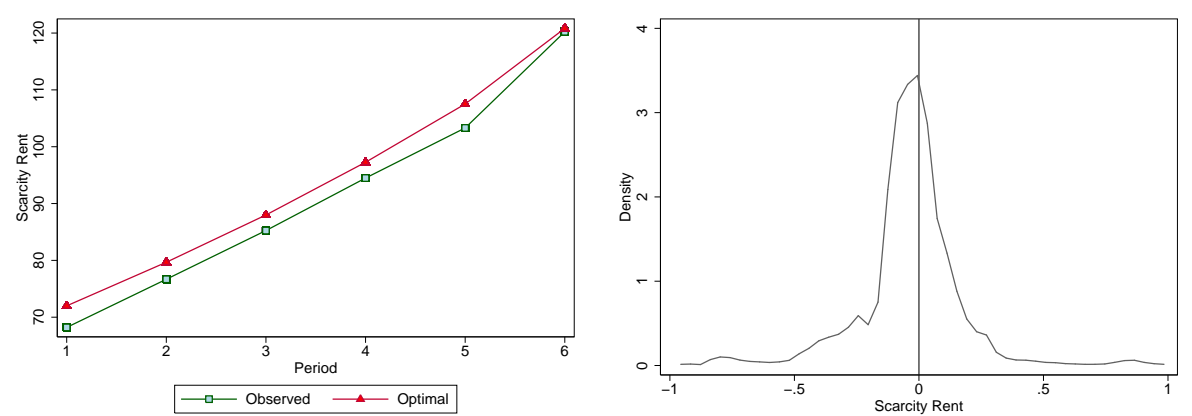

Figure 4: Monopoly

Notes. The left panel of the figure plots the time series of the average observed scarcity rent and the optimal scarcity rent conditional on the average remaining resource stock. The right panel plots the smoothed density of the deviation from the optimal scarcity rent divided by the optimal quantity $\frac{\lambda_{t}-\lambda_{t}^{o}}{q_{t}^{o}}$ (Epanechnikov kernel, bandwidth $=.028)$. We use deviations from the optimal scarcity rent since the optimal scarcity rent differs depending on the period and the remaining resource stock. Deviations are weighted by the optimal quantity to take into account that a unit deviation from the optimum should be given more weight in periods where the expected optimal production is already quite low.

\section{Results}

The experiment was conducted in February 2010 at the CREED laboratory of the University of Amsterdam. Participants were recruited using an online registration system. Most participants were students coming from various disciplines, with the largest fraction (58\%) being formed by economics students. In total, there were 6 sessions (3 for treatment HIGH and 3 for treatment LOW) in which a total of 136 subjects took part (72 for treatment HIGH, 64 for treatment LOW). On average, participants earned 29.27 euros.

In this section, we first take a brief look at the results of the prologue to check if participants were able to independently understand both strategic behavior and dynamic optimization. We then estimate their production function to gain insight into which aspect producers paid most attention to when making their production decision. The next subsection then brings together the prologue and the main part as a second way to investigate what aspect producers paid most attention to. Finally, we examine if differences in the production function are reflected by market outcomes as well. 
Table 2: Unconstrained Oligopoly Production Function

\begin{tabular}{lc}
\hline \hline & $\begin{array}{c}\text { Dependent Variable: } \\
\text { Quantity in period } t\end{array}$ \\
\hline Other producer quantity in $t-1$ & $.1512^{* * *}$ \\
& $(.0386)$ \\
\hline Observations & 2040 \\
Adj. $\mathrm{R}^{2}$ & .1640 \\
\hline \hline $\mathrm{p}<0.1 \% ;{ }^{* *} \mathrm{P}<0.05 \% ;{ }^{* * *} \mathrm{p}<0.01 \%$ &
\end{tabular}

Notes. This table displays a fixed effects regression of period $t$ quantity on other producer quantity in period $t-1$. Fixed effects are included for both individuals and time periods; time-individual fixed effects are omitted because of possible multicollinearity. Standard errors are clustered by individual and reported in parentheses below the associated coefficient. P-values are calculated using two-sided t-tests. The regression uses data from all three rounds; in every round the first period is omitted since lagged quantities are only available from period two onwards.

\subsection{Prologue}

The purpose of the first phase of the prologue (monopoly) was to familiarize participants with the dynamic optimization aspect of the nonrenewable resource problem. In particular, we expected participants to learn at least the basic rule of dynamic optimization, which dictates that scarcity rents should be monotonically nondecreasing over time. Scarcity rents were indeed nondecreasing for $90 \%$ of our participants (or 123/136). Moreover, 89\% (121/136) displayed a significant positive time trend in scarcity rents. ${ }^{26}$ Furthermore, 87\% (118/136) exceeded the earnings corresponding to a constant production schedule. ${ }^{27}$ In fact, the median participant was within 5 cents (or $4 \%$ ) of the maximum (theoretical) pay-off. However, as figure 4 shows, participants display a small tendency to exhaust the resource prematurely: on average they extracted $2.01 \%$ more than the optimal quantity in the first five periods and as a consequence the scarcity rent was $4.80 \%$ lower than the optimal level $(\mathrm{t}(136)=-1.95, \mathrm{p}<0.1)$. This echoes the findings of Brown, Chua, and Camerer (2009) who find that in a dynamic savings experiment, participants also tend to save too little. On the whole, however, most producers were very close to the optimum, suggesting that they managed to achieve at least a basic understanding of dynamic optimization.

\footnotetext{
${ }^{26}$ The trend was estimated using a linear regression of scarcity rent on a constant and a linear time trend; significance was obtained using a two-sided t-test with a significance level of $5 \%$.

${ }^{27}$ More accurately, their earnings exceeded the earnings corresponding to the extraction of $47,47,47,47,46,46$ in periods 1 to 6 respectively.
} 

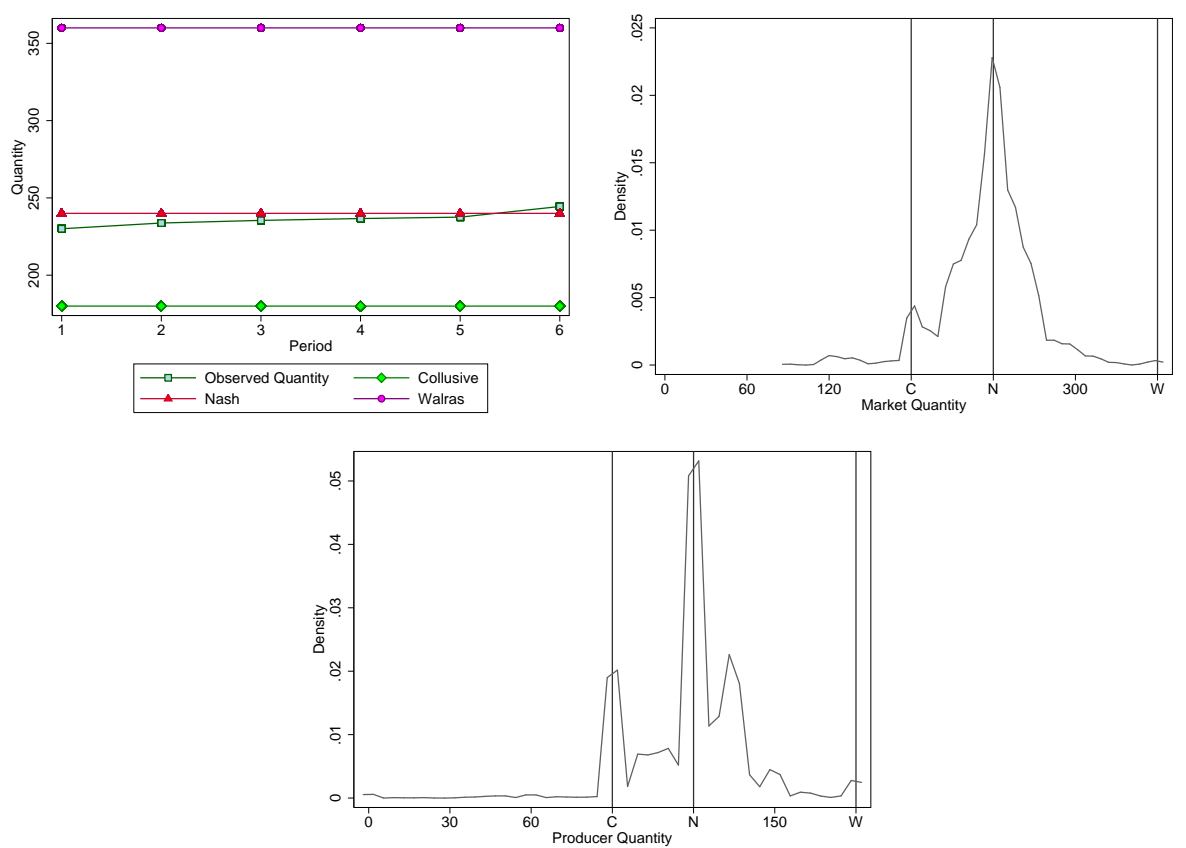

Figure 5: Unconstrained Oligopoly

Notes. The left panel of the figure plots the time series of the average observed market quantities as well as the three benchmarks. The right and lower panels plot the smoothed density of observed market (Epanechnikov kernel, bandwidth $=4$ ) and individual quantities (bandwidth=2) over all periods respectively. $\mathrm{C}, \mathrm{N}$ and $\mathrm{W}$ represent the Cournot, Nash and Walras quantities. 
The purpose of phase two of the prologue (unconstrained oligopoly) was to familiarize participants with the strategic behavior aspect. As the left panel fo figure 5 shows, market production levels were quite close to the Nash benchmark on average. ${ }^{28}$ In terms of the distribution, there is also a small peak at the collusive quantity; moreover at the producer level, production levels are more dispersed than at the market level. On the whole this is not unlike what is commonly observed in oligopoly experiments (see e.g. Engel, 2010). To check if participants understood the strategic behavior aspect, we used a panel regression to estimate their production function. Recall that there is evidence of strategic behavior if producers condition their own production levels on what they expect the other producer to extract. Since we did not elicit expectations in the prologue, we proxy for expectations using last period's other producer quantity. ${ }^{29}$ Table 2 documents the results of the regression. On average, participants increased their production if their rival previously produced a high quantity. Thus, they took the behavior of the other producer into account when making their production decision, which suggests that they also gained some understanding of the strategic behavior aspect.

\subsection{Producer Focus in the Main Part}

We now turn to producer focus in the main part, where both strategic behavior and dynamic optimization were possible. We investigate the degree to which producers pay attention to either dynamic optimization or strategic behavior by estimating their production function. For this purpose we estimate the following panel regression:

$$
\mathrm{q}_{r i t}=\beta * \mathrm{E}\left[\mathrm{q}_{r j t}\right]+\gamma_{1} * \mathrm{~S}_{r i t}+\gamma_{2} * \mathrm{~S}_{r j t}+\mathrm{T}_{t}+\delta_{i}+\epsilon_{r i t}
$$

This equation posits that producer $i$ 's quantity in period $t$ of round $r$ is a function of several variables. $\mathrm{E}\left[\mathrm{q}_{r j t}\right]$ is producer $i$ 's prediction for the quantity of producer $j$ (the other producer);

\footnotetext{
${ }^{28}$ At the market level, production levels were not significantly different from the Nash benchmark either overall or in any individual period. At the producer level the average quantity over all periods was slightly lower than Nash $(\mathrm{F}(1,135)=4.10, \mathrm{p}<0.05)$. The average quantity was also significantly lower in period 1 $(\mathrm{p}<.01)$, period $2(\mathrm{p}<.01)$ and period $3(\mathrm{p}<.1)$, whilst being significantly higher in period $6(\mathrm{p}<.05)$.

${ }^{29}$ This is a good proxy to the extent that participants based their expectations on what the other firm produced in the previous period. See appendix A for evidence that suggests that this is indeed the case.
} 
Table 3: Main Part Production Function

\begin{tabular}{lllll}
\hline \hline & \multicolumn{4}{c}{ Dependent Variable: Quantity } \\
\cline { 2 - 5 } & Coeff. & Std Err. & Coeff. & Std Err. \\
\hline Predicted other producer quantity & $.3050^{* * *}$ & .0809 & $.3340^{* * *}$ & .0632 \\
Stock & $.4269^{* * *}$ & .0422 & $.1890^{* * *}$ & .0629 \\
Other producer stock & $-.0884^{* * *}$ & .0250 & -.0189 & .0157 \\
\hline Observations & \multicolumn{2}{c}{1600} & 1800 \\
Adj. $\mathrm{R}^{2}$ & \multicolumn{2}{c}{.7436} & .4766 \\
\hline \hline
\end{tabular}

* significant at $10 \% ; * *$ significant at $5 \% ; * * *$ significant at $1 \%$

Notes. This table contains the results of a panel regression of quantity on the predicted quantity of the other producer, stock and the stock of the other producer. Period and producer fixed effects are also included but not reported; standard errors are clustered at the producer level. Predictions were only elicited in even rounds; moreover, the final period is omitted from the analysis since all benchmarks are trivially equal to the remaining resource stock in the final period. Thus, the number of observations per individual in all treatments is equal to 25,5 rounds with 5 observations each. P-values are based on two-sided t-tests.

this variable represents the degree to which producer $i$ pays attention to the strategic behavior aspect. $^{30} \mathrm{~S}_{\text {rit }}$ and $\mathrm{S}_{r j t}$ are producer $i$ 's stock and producer $j$ 's stock respectively; these variables represent the dynamic optimization aspect. Finally, the regression also includes time fixed effects $\left(\mathrm{T}_{t}\right)$ and individual fixed effects $\left(\delta_{i}\right)$ to correct for differences between people and periods. ${ }^{31}$ Throughout the analysis, standard errors are clustered by producer..$^{32}$ Note also that the inclusion of the prediction variable means that the analysis will only use data from rounds where predictions were requested (i.e. all even rounds). ${ }^{33}$

Table 3 displays the results of the regression for both treatments. For the dynamic opti-

\footnotetext{
${ }^{30}$ Since producers were asked to make predictions and production decisions simultaneously, there are legit concerns that predictions may be endogenous. This issue is addressed in appendix A both using an Instrumental Variables approach and using lagged other producer quantity as an indirect measure of expectations.

${ }^{31}$ We do not include individual specific time fixed effects since that would greatly increase the number of parameters per individual, which would put too much strain on the data. It is possible to include round fixed effects, but these are never significant in any treatment and including them does not affect the coefficient estimates; hence we do not include them here.

${ }^{32}$ It would have also been possible to do the clustering by matching groups. However, the resulting standard errors are lower and perhaps less reliable because of the relatively small number of matching groups per treatment. Hence we stick to the more conservative estimate.

${ }^{33}$ Another feasible regressor would have been lagged quantity, since it is not infeasible that a producer's production decision would be partially influenced by his previous production decision even after correcting for the other variables. However, including lagged quantity as a regressor would have made the the model dynamic, which would have made unbiased inference very difficult. For the same reason we also excluded lagged predictions (which may be endogenous to lagged production, see appendix A). We also excluded lagged other producer quantity, since its p-value always exceeds .2 and including would have resulted in the removal of the first period of every round from the analysis.
} 
mization variables stock and other producer stock, the results are in line with hypothesis $1 \mathrm{~A}$. Indeed, other producer stock is significant only for treatment LOW, the difference in coefficients is significant at the $5 \%$ level. $^{34}$ The coefficient for stock is also higher for treatment LOW both in absolute size and in terms of p-value; the difference in coefficients is significant at the $1 \%$ level. Moreover, the coefficient for stock is not significantly different from the Nash coefficient for stock in treatment LOW, whereas it is significantly lower at the $1 \%$ level for treatment HIGH (the optimal coefficients are .37 and .33 respectively). ${ }^{35}$ Thus there is evidence that producers were more mindful of the dynamic optimization aspect in treatment LOW than in treatment HIGH.

When it comes to the strategic behavior aspect, results are less clear cut. On the one hand, the results are in the direction predicted by hypothesis 1B: a change in predicted other producer quantity had a larger effect in treatment HIGH than in treatment LOW. On the other hand, the difference between treatments is not significant at conventional levels. ${ }^{36}$

\subsection{Comparing the Prologue and the Main Part}

Thus we have seen that in terms of the production function, the dynamic optimization aspect seemed to be more important in treatment LOW, whereas there was no pronounced pattern for the strategic behavior aspect. Another way to examine producer focus in the main part is to correlate behavior in the main part to behavior in the prologue. Specifically, if hypotheses $1 \mathrm{~A}$ and $1 \mathrm{~B}$ are correct, the degree to which behavior correlates between the prologue and the main part could also depends on the treatment. Behavior in treatment LOW should then be most correlated to behavior in the monopoly phase of the prologue, whereas behavior in treatment HIGH should be most correlated to the unconstrained oligopoly phase.

To test this idea we regressed indicators of behavior and success in the main part on

\footnotetext{
${ }^{34}$ All comparisons between coefficients in table 3 are based on a pooled regression with data from all treatments, where we included interaction terms between treatment dummies and the variables of table 3 (as well as time fixed effects). The difference in coefficients between treatments is significant only if the interaction terms are.

${ }^{35}$ To find the Nash coefficient for stock we repeat the analysis of table 3 but replace actual quantities with the (numerically derived) Nash quantities.

${ }^{36} \mathrm{We}$ also ran two separate sessions where production in the main part was unconstrained. Repeating the regression of table 3 for these sessions gives a higher coefficient (.3941, S.E. .0793) for predicted other producer quantity, although the difference in coefficients with treatment LOW and treatment HIGH was also not significant.
} 
similar indicators from the prologue. From the monopoly part of the prologue we take the difference between the first period scarcity rent and last period scarcity rent (or dispersion) as an indicator of dynamic optimization. For the unconstrained oligopoly part of the prologue we take first period production quantity as a measure of the intention to produce cooperatively. Moreover we take a measure of income in both parts and correlate that with main part income to see if success is also correlated between the prologue and the main part.

Table 4 shows the result of these regressions. Firstly, participants with a high dispersion in the monopoly part of the prologue also had a high dispersion in the main part, but only in treatment LOW. ${ }^{37}$ Participants who were successful in the first part of the prologue were more successful in treatment LOW in terms of income as well. ${ }^{38}$ On the other hand, there is no significant correlation for either the intention to behave cooperatively (first period quantity) or for succes in the second part of the prologue for either treatment. Thus there seems to be some evidence that behavior and success in the monopoly phase are correlated to behavior and success in treatment LOW (but not treatment HIGH); however there is no correlation between the unconstrained oligopoly phase and treatment HIGH (or treatment LOW). Overall, these findings are in line with the results of the previous section; there appears to be a difference between treatments for the importance of the dynamic optimization aspect, but not for the strategic behavior aspect.

\subsection{Market Outcomes in the Main Part}

In the previous sections we saw that the dynamic optimization aspect seemed to be less important in treatment HIGH. If hypothesis $1 \mathrm{~b}$ is true, this means that production levels

\footnotetext{
${ }^{37}$ The results are identical if we use the differential between the highest and lowest scarcity rent instead.

${ }^{38}$ In comparing the unconstrained oligopoly with the main part we correlated overall income in the unconstrained oligopoly to overall income in the main part. However, for the monopoly part there are several complications: (a) because of practice almost all participants were able to do well in the monopoly part of the prologue; as a result there was little variation in the production schedule used in the incentivized round. Moreover, (b) starting from round two participants in the main part could also adopt the production schedule they learned from the other producer in a preceding round. To solve the first problem, we constructed a dummy variable which was equal to one only if the participant managed to run a profit in at least one of his first three practice rounds (the results are similar if we take the first four, five or six practice rounds instead). This split the sample roughly in half, since $57 \%$ of participants managed to run a positive profit in one of the first three practice rounds. To adress possible learning considerations we used only the first round of the main part.
} 

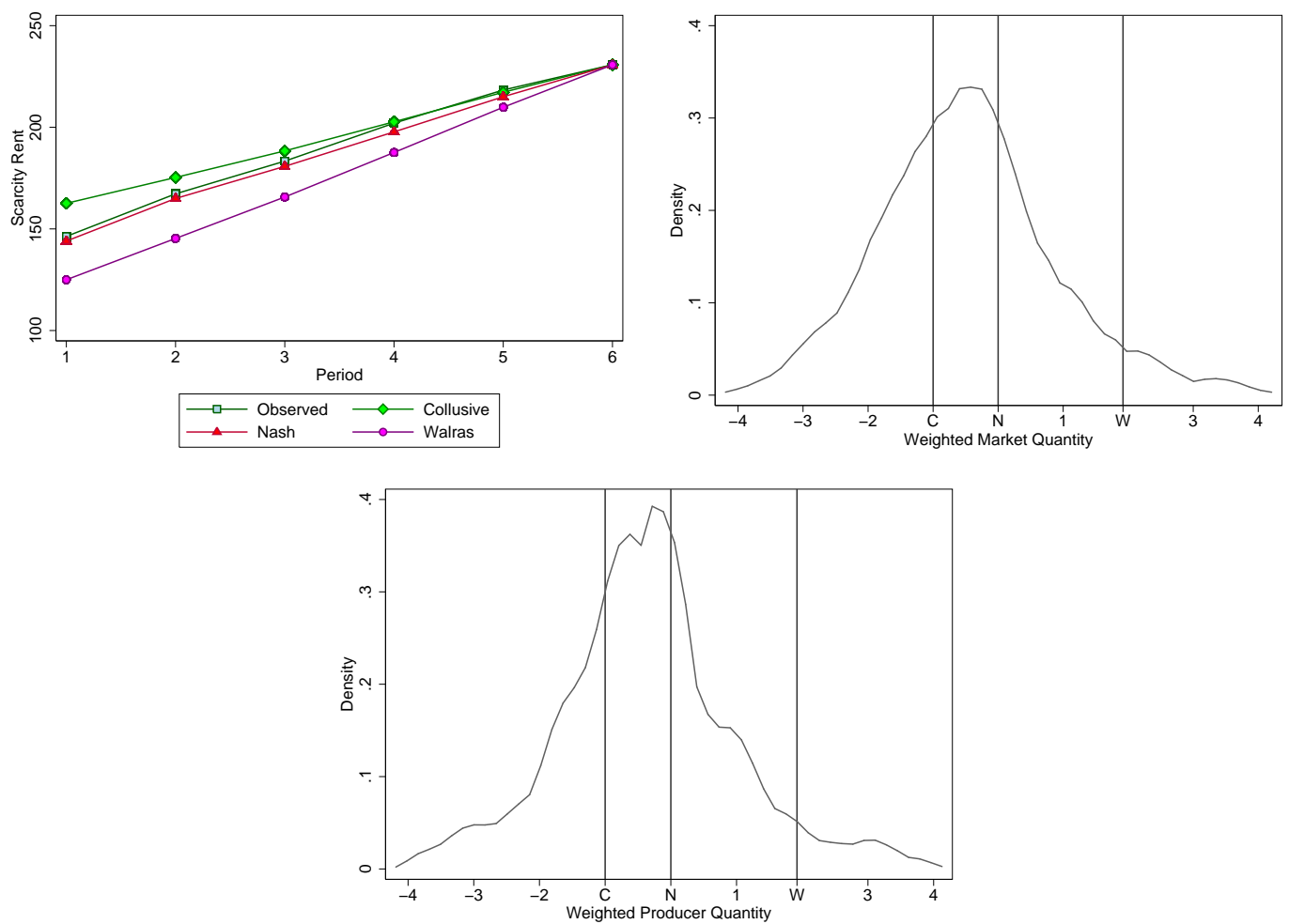

Figure 6: Treatment LOW

Notes. The left panel plots the time series of the average observed scarcity rent as well as the benchmark Nash, Collusive and Walras scarcity rent with respect to the unconstrained Nash price. This is equivalent to subtracting a fixed number $\left(p_{U}^{n}=124\right)$ from the observed and benchmark prices respectively (i.e. $p^{i}-p_{U}^{n}$, where $p^{i}$ is the observed, Nash, Collusive or Walras price respectively). The benchmarks are recalculated every period conditional on the remaining average resource stock. The right panel plots the smoothed density (Epanechnikov kernel, bandwidth $=.26$ ) of the deviation from the Nash quantity weighted by the distance between the Collusive quantity and the Nash quantity (i.e. $\frac{q_{t}-q_{t}^{N}}{q_{t}^{N}-q_{t}^{C}}$ ) in periods one to five. The lower panel does similarly but then for producer quantity (bandwidth=.28). We look at deviations since from period two onwards the three benchmarks are different for every market; we use weights since a unit deviation from the Nash quantity means more in periods where the three benchmarks are closer together. C, N and W represent Cournot, Nash and Walras levels respectively; the Cournot and Nash levels are -1 and 0 by the normalization whereas the Walras differs between markets (average $=1.91$, always bigger than zero). Period 6 is omitted since all benchmarks are equal to the resource stock in this period. 

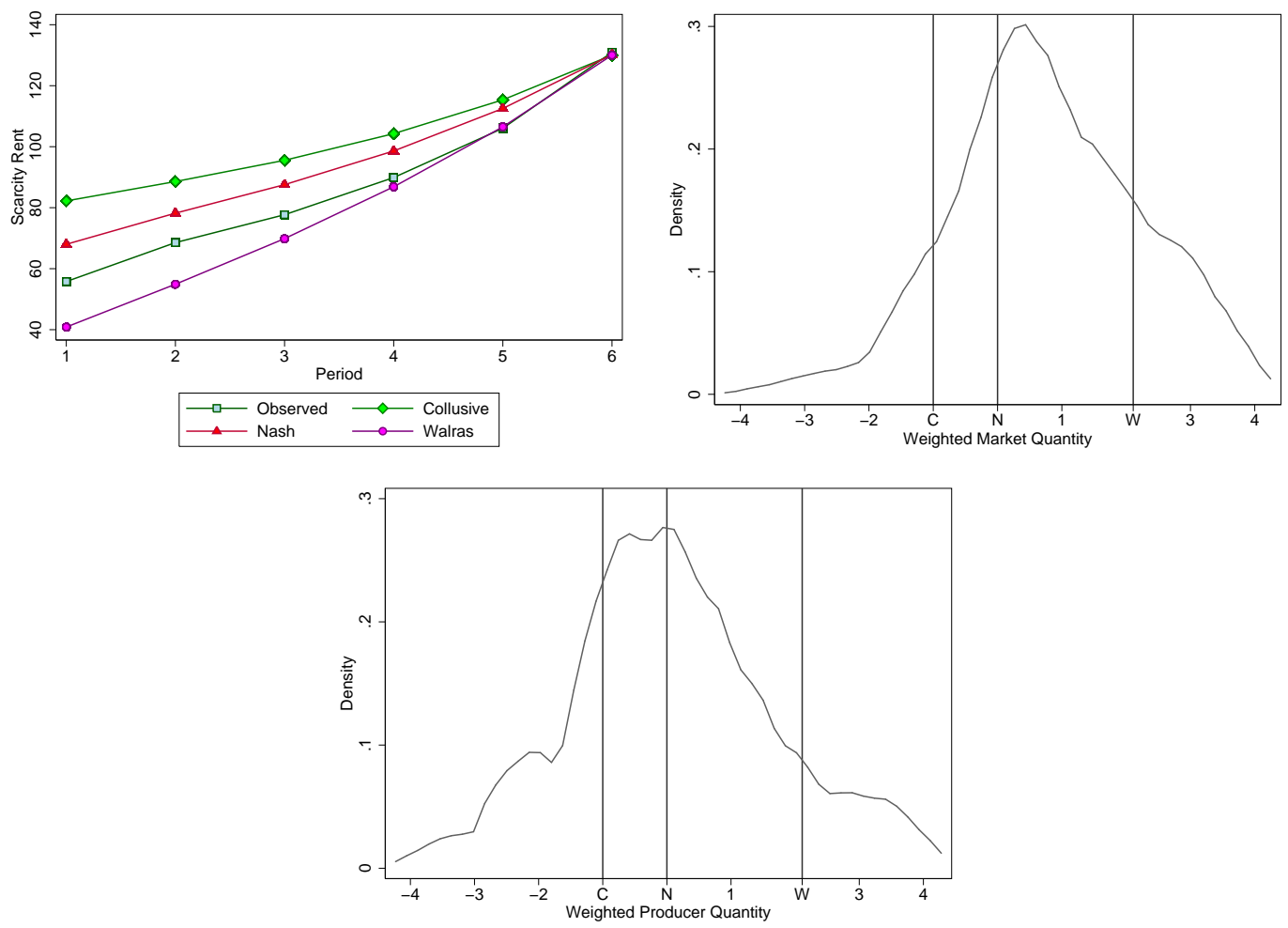

Figure 7: Treatment HIGH

Notes. The left panel plots the time series of the average observed scarcity rent as well as the benchmark Nash, Collusive and Walras scarcity rent with respect to the unconstrained Nash price. This is equivalent to subtracting a fixed number $\left(p_{U}^{n}=124\right)$ from the observed and benchmark prices respectively (i.e. $p^{i}-p_{U}^{n}$, where $p^{i}$ is the observed, Nash, Collusive or Walras price respectively). The benchmarks are recalculated every period conditional on the remaining average resource stock. The right panel plots the smoothed density (Epanechnikov kernel, bandwidth $=.22$ ) of the deviation from the Nash quantity weighted by the distance between the Collusive quantity and the Nash quantity (i.e. $\frac{q_{t}-q_{t}^{N}}{q_{t}^{N}-q_{t}^{C}}$ ) in periods one to five. The lower panel does similarly but then for producer quantity (bandwidth=.19). We look at deviations since from period two onwards the three benchmarks are different for every market; we use weights since a unit deviation from the Nash quantity means more in periods where the three benchmarks are closer together. C, N and W represent Cournot, Nash and Walras levels respectively; the Cournot and Nash levels are -1 and 0 by the normalization whereas the Walras differs between markets (average $=2.11$, always bigger than zero). Period 6 is omitted since all benchmarks are equal to the resource stock in this period. 
Table 4: Comparing the Prologue and the Main Part

\begin{tabular}{lcc}
\hline \hline & LOW & HIGH \\
Monopoly dispersion & Dependent Variable: main part dispersion \\
& $.6469^{* * *}$ & .1589 \\
& $(.2121)$ & $.3823)$ \\
Unconstrained Oligopoly first period quantity & Dependent Variable: main part first period quantity \\
\cline { 2 - 3 } & -.0365 & .0930 \\
Monopoly income & $(.2227)$ & $(.1180)$ \\
Unconstrained Oligopoly income & Dependent Variable: main part income \\
& $.5940^{* *}$ & .2463 \\
Observations & $(.2274)$ & $.1554)$ \\
\hline * significant at 10\%; & .0287 & .0441 \\
& $(.0478)$ & 72 \\
\hline
\end{tabular}

Notes. This table displays the results of four separate regressions. Dependent (and independent) variables are main part income (phase one income), main part income (phase two income), main part dispersion (phase one dispersion) and main part first period quantity (phase two first period quantity) respectively. Standard errors are reported in parentheses below the associated coefficient; p-values are calculated using two-sided t-tests.

should be closer to the Walras benchmark in treatment HIGH as well. Figures 6 and 7 and table 5 give an overview of scracity rents and production levels in the main part. For treatment HIGH, average scarcity rents are lower than the Nash level in all periods and become indistinguishable from Walras in periods 4 and $5 .{ }^{39}$ For treatment LOW, the scarcity rent is indistinguishable from the Nash level in the first two periods at the $5 \%$ level, but subsequently increases to higher levels, until it becomes significantly higher than Nash and indistinguishable from the Collusive level in periods 4 and 5. Thus, participants in treatment HIGH were closer to the Walras benchmark than participants in treatment LOW. This is exactly what one would expect if producers paid less attention to the dynamic optimization aspect in treatment HIGH (hypothesis 1b); the effect is particularly pronounced in periods 4 and 5 .

Thus producers in treatment HIGH are closer to the Walras benchmark than producers in treatment LOW on average. The right and lower panels of figures 6 and 7 show that a similar pattern holds for the distribution as a whole. The peak of the distribution of both treatments lies close to the Nash level both at the producer level and at the market level, but it falls slightly towards the Collusive side of the Nash level in treatment LOW and towards

\footnotetext{
${ }^{39}$ Since scarcity rents and prices are a constant affine transformation of market quantities, the test statistics for market quantities, prices and scarcity rents are identical.
} 
Table 5: Main Part Market Quantity and Benchmarks

\begin{tabular}{|c|c|c|c|c|}
\hline \multicolumn{5}{|c|}{ Treatment LOW $(\mathrm{N}=320)$} \\
\hline Period & Average Quantity & Nash & Collusive & Walras \\
\hline \multirow[t]{2}{*}{1} & 101.70 & 100 & $85^{* * *}$ & $123^{* * *}$ \\
\hline & $(2.192)$ & $(2.192)$ & $(2.192)$ & $(2.192)$ \\
\hline \multirow[t]{2}{*}{2} & 80.75 & 83.04 & $72.70 * *$ & $102.69 * * *$ \\
\hline & $(2.322)$ & $(2.691)$ & $(2.596)$ & $(2.692)$ \\
\hline \multirow[t]{2}{*}{3} & 64.65 & 67.23 & $59.62^{*}$ & $82.32^{* * *}$ \\
\hline & $(1.338)$ & $(2.184)$ & $(2.149)$ & $(2.476)$ \\
\hline \multirow[t]{2}{*}{4} & 45.975 & $50.28^{* *}$ & 45.31 & $60.40 * * *$ \\
\hline & $(1.149)$ & $(1.270)$ & $(1.146)$ & $(1.595)$ \\
\hline \multirow[t]{2}{*}{5} & 29.67 & $32.97^{* * *}$ & $30.77^{*}$ & $38.14^{* * *}$ \\
\hline & $(1.924)$ & $(.737)$ & $(.494)$ & $(1.029)$ \\
\hline \multirow[t]{2}{*}{6} & 17.21 & 17.27 & 17.27 & 17.27 \\
\hline & $(2.646)$ & $(.037)$ & $(.037)$ & $(.037)$ \\
\hline \multicolumn{5}{|c|}{ Treatment High $(\mathrm{N}=360)$} \\
\hline Period & Average Quantity & Nash & Collusive & Walras \\
\hline \multirow[t]{2}{*}{1} & 192.22 & $180^{* * *}$ & $166^{* * *}$ & $207^{* * *}$ \\
\hline & $(3.686)$ & $(3.686)$ & $(3.686)$ & $(3.686)$ \\
\hline \multirow[t]{2}{*}{2} & 178.74 & $168.79 * * *$ & $159.43^{* * *}$ & $193.10^{* * *}$ \\
\hline & $(1.940)$ & $(2.448)$ & $(2.510)$ & $(2.510)$ \\
\hline \multirow[t]{2}{*}{3} & 170.30 & $160.44^{* *}$ & $152.46^{* * *}$ & $178.15^{* *}$ \\
\hline & $(2.070)$ & $(3.138)$ & $(3.186)$ & $(3.186)$ \\
\hline \multirow[t]{2}{*}{4} & 158.11 & $149.40^{* * *}$ & $143.71^{* * *}$ & 161.13 \\
\hline & $(1.567)$ & $(2.004)$ & $(2.022)$ & $(2.022)$ \\
\hline \multirow[t]{2}{*}{5} & 141.96 & $135.46^{* * *}$ & $132.63^{* * *}$ & 141.49 \\
\hline & $(2.492)$ & $(1.318)$ & $(1.219)$ & $(1.219)$ \\
\hline \multirow[t]{2}{*}{6} & 117.03 & $117.97^{* *}$ & $117.97^{* *}$ & $117.97^{* *}$ \\
\hline & $(4.571)$ & $(.357)$ & $(.357)$ & $(.357)$ \\
\hline
\end{tabular}

Notes. This table compares the observed average market quantity per period to the Nash, Collusive and Walras benchmark for every treatment. Since the Collusive and Walras quantities are unique up at the market level, we recalculate these benchmarks for every period conditional on the remaining market stock for every market. The Nash quantity depends also on the distribution of stocks within the market; hence we recalculate the Nash benchmark for every producer individually. For this purpose, the Nash benchmarks are calculated numerically for every data point conditional on period, producer stock and other producer stock and then summed over both producers on the market. In the first period, all benchmark quantities are integers since all producers have the same resource stock and only integer amounts can be produced. Standard errors are clustered at the matching group level. Significance is based on two-sided t-tests. 


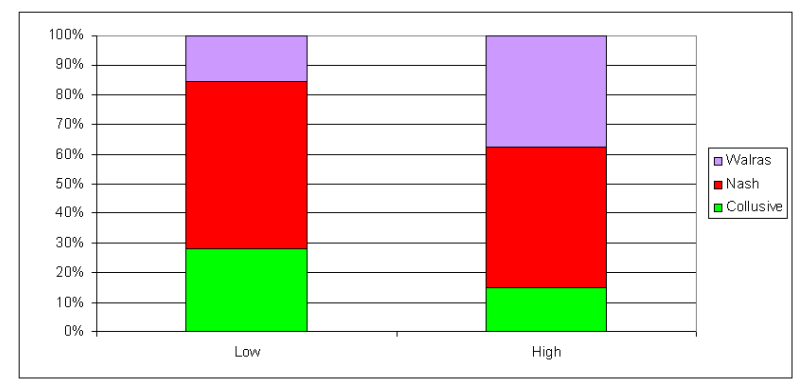

Figure 8: Producers Categorized by Benchmark

Notes. The figure gives the percentage of producers in both treatments that are best approximated by each benchmark. We approximated the production strategy of the three benchmarks as a linear function of stock and a constant. We then compared the log-likelihood of each of the three alternatives for every producer, and put every producer in the category that best fit her behavior.

the Walras the right in treatment HIGH. In terms of market (producer) production levels, $70.5 \%(62.4 \%)$ of all production levels are higher than the Nash benchmark in treatment HIGH, whereas the respective percentages are $28.3 \%$ (30.5\%) for treatment LOW. Moreover, figure 8 shows that if producers are classified by type, a larger share is classified as Walras in treatment HIGH compared to treatment LOW $\left(\chi^{2}(1)=7.12, \mathrm{p}<0.01\right) .{ }^{40}$ This once again suggests that producers were closer to the Walras benchmark in treatment HIGH than in treatment LOW.

Thus, the evidence so far seems to suggest that -in terms of benchmarks- subjects produced more aggressively in treatment HIGH. To see if this is also reflected by their earnings, we compare average realized earnings to potential earnings in the Nash benchmark and weigh this using the distance between the Nash benchmark and the Collusive benchmark. This results in the normalized earnings index $Y_{n o r m}=\frac{Y-Y_{n}}{Y_{c}-Y_{f}}$, where $Y_{n}$ is the theoretical Nash profit, $Y_{c}$ is the theoretical Collusive profit and $Y$ is actual income. ${ }^{41}$ The average index is equal to -6.70 for treatment HIGH and -1.72 for treatment LOW, the difference is significant at the $1 \%$ level (Mann-Whitney, $\mathrm{z}(64,72)=6.422)$. This shows that in terms of the index, earnings were significantly lower in treatment $\mathrm{HIGH}$, which is in line with the finding that

\footnotetext{
${ }^{40}$ For this test we classify producers as either Walras or non-Walras and then compare the difference in fractions between treatments. If we classify producers as either Collusive or non-Collusive, we find no significant differences. If we allow for three categories, the difference is significant.

${ }^{41}$ It is not possible to compare realized earnings levels directly because of difference in stock levels, fixed costs and conversion rates.
} 
producers were most competitive (i.e. closer to Walras) in treatment HIGH. ${ }^{42}$

In summary, we have seen that producers paid less attention to the dynamic optimization aspect in treatment HIGH and that this induced them to produce closer to the Walras benchmark than producers in treatment LOW. At the same time, the experience of the prologue allowed most participants to tackle the Hotelling problem in the main part quite well. As a result, scarcity rents are actually increasing in both treatments, in line with the Hotelling rule and contrary to the findings of most previous empirical studies. Importantly, however, producers in treatment HIGH deviate most from the Nash benchmark and do so in the direction predicted by hypothesis 2 . Thus, even producers who -based on the evidence of treatment LOW- should be able to approximate the Nash time path almost perfectly still shift their focus away from dynamic optimization if their stock levels are relatively high.

\section{Conclusion}

The most important theoretical result in the field of nonrenewable resource economics is the Hotelling rule, which states that scarcity rents should increase over time at the rate of interest. However, the Hotelling rule has received little empirical support. In this study, we propose that the failure of the Hotelling rule can be explained by the multifacetedness of the Hotelling framework. We argue that the nonrenewable resource problem consists of many different aspects (e.g. exploration, strategic behavior, technological developments, dynamic optimization etc.) and that in practice, producers may not be willing or able to take every aspect fully into account. Moreover we argue that the degree to which a nonrenewable resource producer pays attention to a given aspect of the resource problem depends on the size or longevity of her resource stock. In particular, we argue that for a relatively scarce resource it pays off for producers to compute a dynamically optimal production path. However, for a more abundant resource, computing a dynamically optimal production path may be infeasible, non-salient or

\footnotetext{
${ }^{42}$ Interestingly, average earnings were below the Nash level in both treatment HIGH and treatment LOW, despite the finding that in treatment LOW average scarcity rents were never significantly below the Nash level. A likely explanation is that there were several producers may occasionally have made a mistake, which resulted in lower earnings. This idea is supported by the right and lower panels of figures 6 and 7; a substantial portion of producers produced quantities which were below the collusive benchmark or above the Walras benchmark, which can never be optimal.
} 
suboptimal from a cost-benefit perspective. Indeed, producers with a relatively high stock should focus more on other aspects of the decision problem, such as strategic behavior. These producers will then (partly) ignore the dynamic consequences of their extraction decision, which results in suboptimally low prices and the failure of the Hotelling rule.

This argument is supported by the results of a nonrenewable resource duopoly experiment. In a treatment where resources are relatively scarce (treatment LOW), producers put more weight on dynamic optimization variables in their production function compared to a treatment where resources are relatively abundant (treatment HIGH). Similarly, behavior and earnings in treatment LOW are correlated to behavior and earnings in a preceding part of the experiment where only dynamic optimization is relevant (nonrenewable resource monopoly); for treatment HIGH there is no such correlation. There is also some evidence suggesting that producers pay more attention to strategic behavior in treatment HIGH. These differences in production behavior are reflected by market outcomes as well. In treatment HIGH, scarcity rents are persistently lower than the Nash level because producers focus less on dynamic optimization, making them produce closer to the unconstrained levels. On the other hand, in treatment LOW scarcity rents are very close to the Nash level.

In terms of real world markets, the fact that nonrenewable resources have always beens relatively abundant may have shifted producer focus away from the dynamic optimization aspect, leading to suboptimally high extraction rates and the failure of the Hotelling rule. At the same time, we do not believe that this is the whole story; in the experiment scarcity rents still increase in both treatments. A full explanation of the failure of the Hotelling rule may also require other elements, including for example the discovery of new deposits, capacity constraints or technological progress. In future work, it could be worthwhile to use the experimental approach to try to disentangle the relative explanatory power of these elements. Indeed, we believe that experimental data can serve as a complement to field data to aid the profession in gaining a better grasp of the mechanisms driving the behavior of producers on nonrenewable resource markets. 


\section{Appendix A: Re-examining Predictions}

In this section we take a closer look at the predictions ellicitation procedure. Directly asking participants what they expect the other producer to extract gives rise to at least two possible concerns. For one, asking for predictions directly may lead to a false consensus or reciprocity effect (see e.g. Croson, 2000). In the context of this experiment, this effect could mean that participants might base their expectation of the other firm's production on their own production level. Since we are interested in the opposite effect, this means that we have to take possible reverse causality into account when investigating producer dynamics by means of expectations. Moreover, another problem with eliciting expectations directly is that the elicitation procedure itself may change behavior in a round (see e.g. Gächter and Renner, 2010).

In field data, reverse causality issues tend to be addressed using an instrumental variables (IV) approach. A good instruments should (a) have a causal impact on the instrumented variable (period $t$ predictions) and (b) be uncorrelated to the dependent variable (period $t$ production). We can exploit the panel structure of the data and use lagged variables as instruments. One variable variable that meets this criteria is lagged other producer quantity. ${ }^{43}$

Table 6 gives the results of the IV approach; we also repeat the regression of table 3 without period one to make sure that any differences are not due to to the removal of the first period. The first stage estimates show that last period's other producer quantity is indeed strongly correlated to this period's prediction in all three treatments. The estimated coefficients for the prediction variable in stage 2 are approximately half the size of the coefficients for OLS. As a consequence, they are no longer significantly different from zero at the $5 \%$ level. This suggests that the false consensus effects may have had a sizable impact on the predictions that participants made. At the same time, using the IV approach does not qualitatively affect the results; hypothesis $1 \mathrm{~B}$ still does not receive any support from the data, whereas hypothesis 1A strongly does. Indeed, for the dynamic optimization variables stock and other

\footnotetext{
${ }^{43}$ There is a correlation between producer quantity and lagged other producer quantity, but it dissapears if corrected for current period prediction. This suggests that any effect lagged other producer quantity has on current production runs through predictions, which makes it a good instrument. Also, the impact of lagged other producer quantity on current prediction is credibly causal, since it is unlikely for a producer to base his on the other producer's next period prediction, especially since predictions were never made public.
} 
producer stock the results of stage 2 are very close to the results of OLS. Thus, the main results still hold: the coefficient for stock is still significantly larger for treatment LOW; the stock coefficient for treatment LOW is not significantly different from the Nash coefficient whereas the coefficient for treatment HIGH is significantly smaller; also the effect of other producer stock is significant at the $1 \%$ level in treatment LOW but not significant for treament

\section{HIGH. ${ }^{44}$}

To examine if the elicitation procedure itself also influenced behavior in the experiment, we can compare rounds with expectations to rounds where expectations were not elicited. For this purpose we repeat the regression of table 3 but include a dummy for prediction rounds and interact this dummy with all $\mathrm{x}$-variables. Since we have no data on predictions for rounds where predictions were not asked, we use last period's other firm quantity as a proxy. The first stage regression in table 6 showed that this variable is highly correlated to prediction and may as such be a useful proxy. Table 7 gives the results of this regression. The most important thing to note is that none of the interaction terms are significant. This suggests that the elicitation procedure itself may not have significantly affected producer behavior in this experiment. ${ }^{45}$

\section{Appendix B: Experimental Instructions}

This section contains the instructions and questions used in treatment HIGH of the experiment for both the prologue and the main part. Part I and part I refer to phase one and phase two of the prologue respectively, whereas part III refers to the main part. The instructions for treatment LOW were identical except that stock, fixed costs and the conversion rate were different in the main part (part III). An example of a decision screen is provided at the end of this appendix.

\footnotetext{
${ }^{44}$ However, the difference in coefficients is no longer significant.

${ }^{45}$ We also examined if the distribution of quantities differed between rounds with and without predictions; however we found no differences.
} 
Table 6: Production Function using Instrumental Variables

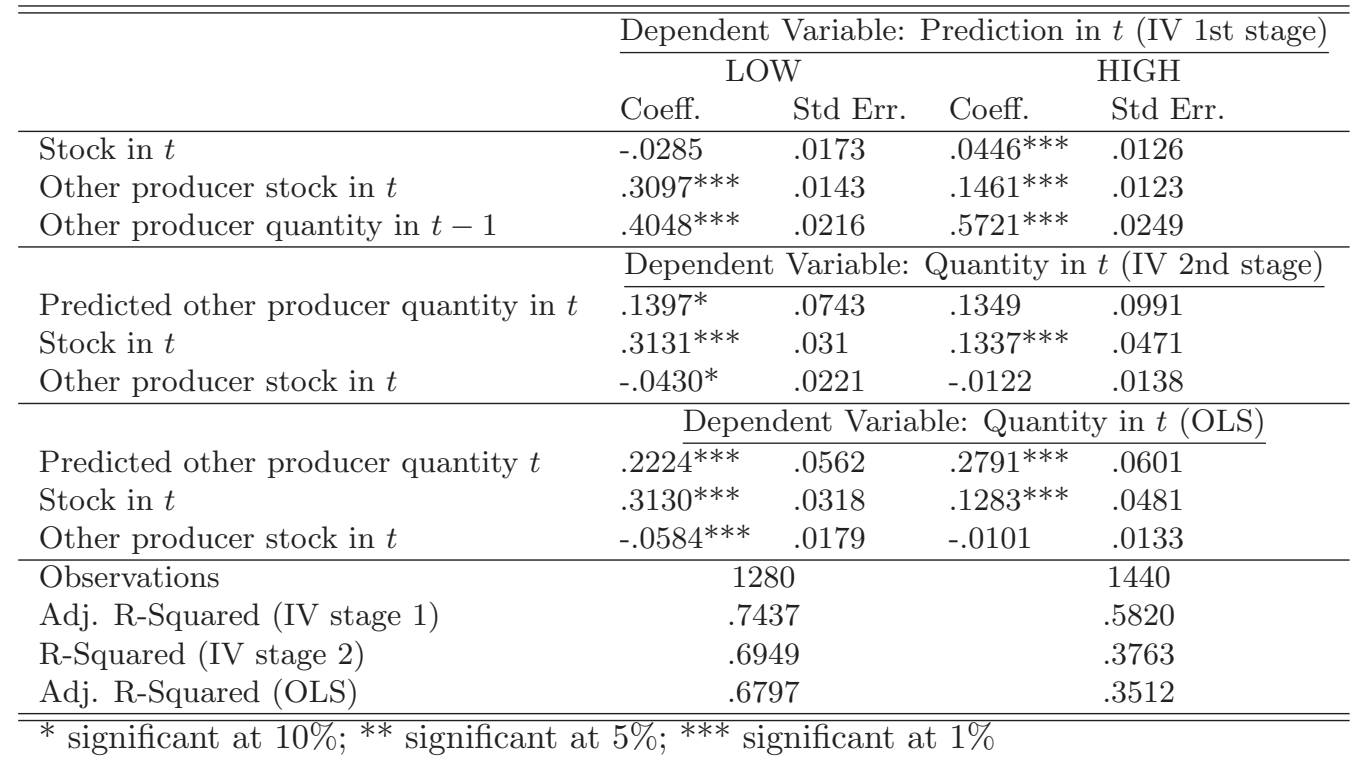

Notes. This table provides the result of an instrumental variables or two stage least squares approach as well as OLS. The first stage of IV consists of a regression of predicted other producer quantity on stock, other producer stock and lagged other firm quantity (the instrument). The second stage of IV is a regression of quantity on the predicted other producer quantity (the instrumented variable), stock and the stock of the other producer. Both stages also contain period and producer fixed effects; standard errors are clustered at the producer level. For OLS, we repeat the regression of table 6 with period 1 removed Predictions were only elicited in even rounds; moreover the first period is omitted because of the use of a lagged variable. The final period is omitted from the analysis since all benchmarks are trivially equal to the remaining resource stock in the final period. Thus, the number of observations per individual in all treatments is equal to 20,5 rounds with 4 observations each. P-values are based on two-sided t-tests.

Table 7: Production Function (Expectations vs no Expectations rounds)

\begin{tabular}{|c|c|c|c|c|}
\hline & \multicolumn{4}{|c|}{$\frac{\text { Dependent Variable: Quantity in } t}{\text { LOW }}$} \\
\hline & Coeff. & Std Err. & Coeff. & Std Err. \\
\hline Other producer quantity in $t-1$ & .0122 & .0324 & .0277 & .0412 \\
\hline Stock in $t$ & $.2815^{* * *}$ & .0217 & $.1795^{* * *}$ & .0281 \\
\hline Other producer stock in $t$ & .0019 & .0111 & -.0144 & .0189 \\
\hline Predictround $\mathrm{x}$ other producer quantity in $t-1$ & .0452 & .0481 & .0537 & .0717 \\
\hline Predictround $\mathrm{x}$ stock & .0210 & .0151 & -.0490 & .0334 \\
\hline Predictround $\mathrm{x}$ other producer stock & -.0014 & .0171 & .0285 & .0242 \\
\hline Observations & \multicolumn{2}{|c|}{2560} & \multicolumn{2}{|c|}{2880} \\
\hline R-Squared & \multicolumn{2}{|c|}{.6676} & \multicolumn{2}{|c|}{.3347} \\
\hline
\end{tabular}

Notes. This table provides the result of a regression of quantity on lagged other producer quantity, stock and the stock of the other producer as well as the same variables interacted with a dummy (predictround) which is equal to one for all rounds where predictions were made. The regression also contains period and producer fixed effects (the former are also interacted with the predictround dummy); standard errors are clustered at the producer level. The first period is omitted because of the use of a lagged variable; the final period is omitted since all benchmarks are then trivially equal to the remaining resource stock. Thus, the number of observations per individual in all treatments is equal to 40,10 rounds with 4 observations each. P-values are based on two-sided t-tests. 


\section{Introduction Part I}

In part 1 of this experiment, you are the manager of a firm. In particular, you will have to decide on the quantity that your firm is going to produce. Your firm is the only active firm on the market (i.e. it is a monopolist) and as such only your decision determines the market price. In this part of the experiment, the minimum market price is 0 and the maximum market price is 372 . Moreover, increasing your quantity by 1 will lower the price by 2 . Quantity and price in turn determine revenue according to the following formula:

\section{Revenue $=$ Price X Quantity}

The payment you receive at the end of the experiment will be based on total revenue. This part of the experiment consists of several rounds. Each round in turn consists of 6 periods. In each period you have to decide what quantity your firm is going to produce. After 6 periods, the round will end and your pay-off over the round will be determined. After this a new round will start, which will again have 6 periods.

You may have noticed that there is a calculator at the bottom of the screen. It can be used to calculate what will be the price and revenue level if you pick a certain quantity. You can now go to the next page of the instructions. Note that you can always return to this page later by clicking on the blue headers at the top of this page (only the pages you have already been to can be accessed).

\section{The Payment Mechanism}

In this experiment, revenue earned in earlier periods is more valuable than revenue earned in later periods. One way to think about this is that your revenue will be put on a bank account, where it will earn $10 \%$ interest per period. The final column in the calculator describes exactly how much a given level of revenue earned in a certain period will be worth in terms of End Income. For example, a quantity of 54 produced in period 1 yields a revenue of 14256, which will yield an end income of 22959 at the end of the round. The same numbers can also be accessed using the calculator by filling in 54 for first period quantity. 
At the end of every round, your firm will calculate its total end income by adding up end income levels of all 6 periods. However, your firm also has a fixed cost equal to 98000, which will have to be paid at the end of every round. This fixed cost is unavoidable and will have to be paid regardless of the amount you produced over the round. Think of this amount as the total cost of maintaining a factory over the whole round. As a result, your payment at the end of a round will be determined according to the following formula:

\section{Payment $=$ Total End Income - Fixed Cost}

At the end of the experiment, the points from all rounds will be converted into euros at a rate of 2000 points per euro, such that 1000 points are worth 0,50 euros. Be assured though that over the whole experiment it will not be possible to lose money. A negative pay-off over a round can be compensated by a positive pay-out in another round, in another part of the experiment, or by the show-up fee (7 euros), with a miminimum possible pay-off of zero over the whole experiment. Note, however, that this is very unlikely to happen.

\section{Resource Stocks}

One thing we have neglected so far is the production process. Producing one unit of your firm's good will require one unit of resource. Over each round, only 280 units of resource are available, so that at most 280 units can be produced. Thus, consuming one unit of resource in the first period means that you will not be able to use it in any of the following periods. At the start of each new round, your resource stock will be replenished.

One thing to note about the resource stock is that you do not have to use it all. Likewise, it is not necessary to produce in every single period. At the same time, it is also very well possible to use up your whole resource stock and produce in all periods. Before we start the actual experiment, you will have some time to practice to familiarize yourself with this set-up.

As a final comment, be sure that you understand the difference between period and round, and also between revenue, end income and payment. One round consists of 6 periods. Similarly, revenue is what your firm earns every period, end income is what your firm's revenue of a period will be worth at the end of the round (i.e. after taking interest into account) and 
payment is the total amount of points you get at the end of a round.

To make sure you understand these ideas, we have a few questions for you.

\section{Question 1}

The first question is about the price mechanism. Suppose your firm is going to produce $\mathbf{5 8}$. What will be the market price? (Integer between 0 and 372). Tip: use the calculator (any period will do, since the price does not depend on the period)!

\section{Question 2}

Which of the following statements is true? If you produce 55 in both period 2 and period 3 , you will have...

1. Different prices, revenues and end incomes in both periods

2. The same price and end income in both periods and a higher revenue in period 3

3. The same price and end income in both periods and a higher revenue in period 2

4. The same price and revenue in both periods and a higher end income in period 2

5. The same price and revenue in both periods and a higher end income in period 3

6. The same price, revenue and end income in both periods

\section{Question 3}

Which of the following statements is false? It is possible to...

1. Produce zero in some periods

2. Produce something in all periods

3. Over all periods produce less than your stock

4. Over all periods produce as much as your stock

5. Over all periods produce more than your stock 


\section{Question 4a}

Now suppose your firm has arrived in period 5 (out of 6 ) and still has a stock of 26 . However, you are doubting between two different options. Option A entails producing 19 in period 5 and 7 in period 6 . Option B would be to produce 7 in period 5 and 19 in period 6 . What option would yield the highest end income?

\section{Question 4b}

Suppose you have indeed decided to produce 19 in period 5 and 7 in period 6 . What end income is your firm going to earn?

\section{End of Instructions}

You are now ready to start the experiment. By clicking on the next link, you will go to a practice session as soon as everyone has finished the instructions. The results you obtain during practice will not count towards your pay-out at the end of the experiment. Practice time will last for approximately 10 minutes; during this time you can work through as many rounds as you like. After the practice session has ended you will move on to the part where earnings will be paid out. This part is identical to practice, except that there will be only 1 round. All results obtained in the practice session will be saved and made available during the real experiment, so use practice time to familiarize yourself as well as possible with the set-up.

One more thing to note is that the bottom right corner of the screen will show a timer. You can see an example of the timer in the bottom of right of this screen. The timer indicates the amount of time you have left to make a decision in the current period. In this part of the experiment, you will have a maximum of 40 seconds to make your decision. If you fail to make your decision in time, you will automatically produce zero and move on to the next period. The timer is reset in every period, regardless of how much time you spent in the preceding period. Finally, note that it in many cases only a small fraction of the required time might be needed to make a decision. 


\section{Instructions Part II}

We will now start with the second part of this experiment. In this part of the experiment, you will be the manager of a firm, like in part I. However, several other aspects have changed. For one, you now face competition from one other firm. For another, you will have an unlimited amount of resources to produce with. Moreover, fixed costs will be slightly higher. These changes will be explained in greater detail below and on the next page.

\section{Dealing with other firms}

Firstly, you will now face competition from another firm. The decisions for the other firm will be made by another participant of this experiment. The other firm you face will be the same in every period of the same round but will change in each new round. Moreover, decisions will be made simultaneously, so that you will not know the other firm's production level until after the end of the period, just like the other firm will not know your production level. Similarly, you will not know with whom you will be matched, like others will not know with whom they will be matched. Anonymity is ensured.

As a result of the presence of the other firm, the effect of your quantity on market price has changed. In particular, a one unit increase in production by either you or the other firm will now lower the market price by 1 . Moreover, the price will now be between 0 and 360 . The calculator has been changed and will now be able to also take the decisions of the other firm into account. You will be able to practice with the new situation in one of the exercises.

\section{Resources and Earnings}

Another difference between part II and part I is that you will no longer have a limited stock of resources. As a result, producing a high amount in an early period will no longer limit your production in later periods. The final difference with the first part is that fixed costs are now equal to 100000. Other than that, the payment mechanism in this part of the experiment is identical to the mechanism used in the first part. Your payment after each round is still determined using the following formula: 


\section{Payment $=$ Total End Income - Fixed Cost}

Your payment will be converted into euros at a rate of 10000 points per euro, such that 1000 points are worth 0,10 euros. Moreover, interest will still be equal to 10\%. Before going to the experiment, we would like to ask two checkup questions.

\section{Question 1}

This question will make use of the following table. The table can be read as follows: the left column contains your production decision (in red). The top row contains the production decision of the other firm (in blue). The cells in the table indicate what level of revenue your firm will earn (again in red) for the associated combination of production levels by your firm and the other firm. Moreover, the cells also contain the revenue that the other firm will earn (in blue). For example, to look up your revenue in case the other firm produced 60 and your firm produced 120, you would have to go right from 120 and down from 60, where you would find that you would earn a revenue of 216 and the other firm would get 108 .

There are a few more things to note about the table. For one, note that the numbers in the table are revenues, which are equal to end income only in the last period. For another, it is important to note that although the set-up for this question is identical to the set-up used in the experiment itself, we have chosen only a few values as examples. For example, in the actual experiment you would also be able to produce 119 or 121 (or any other amount). Moreover, we have underlined the quantity that will give you the highest revenue keeping the other firm's production level constant. In some cases, there may be two such quantities in the table; however, this holds in the table only because of the particular values used for this example. Finally and importantly, the last two digits have been removed from the revenue numbers in the table. Thus, for example 180 would actually be 18000 , and the latter is what you would have to fill in below.

\section{Question 1}

Suppose the other firm produced 60. What revenue would you earn if you produced $120 ?$ 


\begin{tabular}{|c|c|c|c|c|c|c|c|c|}
\hline & \multicolumn{7}{|c|}{ Other } \\
\hline & & 180 & 150 & 120 & 90 & 60 & 30 & 0 \\
\hline \multirow{7}{*}{ Self } & 180 & 00 & $54 \quad 45$ & 10872 & 16281 & 21672 & $\underline{270} 45$ & $\underline{324} 0$ \\
\hline & 150 & 4554 & 9090 & 135108 & $\underline{180} 108$ & $\underline{225} 90$ & $\underline{270} 54$ & 3150 \\
\hline & 120 & 72108 & $\underline{108} 135$ & 144144 & $\underline{180} 135$ & 216108 & 25263 & 2880 \\
\hline & 90 & 81162 & $\underline{108} 180$ & 135180 & 162162 & 189126 & 21672 & 2430 \\
\hline & 60 & 72216 & 90225 & 108216 & 126189 & 144144 & 16281 & 1800 \\
\hline & 30 & 45270 & 54270 & 63252 & 72216 & 81162 & 9090 & 990 \\
\hline & 0 & 0324 & $0 \quad 315$ & $0 \quad 288$ & $0 \quad 243$ & $0 \quad 180$ & 099 & $\begin{array}{ll}0 & 0\end{array}$ \\
\hline
\end{tabular}

Now suppose the other firm produced 90. Firstly, what quantity should you produce to get the highest revenue for you? What quantity should you produce to get the highest revenue for the other? And finally, what quantity would yield the highest combined revenue? Hint: sometimes multiple answers may be possible.

\section{Question 2}

In the previous question, you were asked what quantity would yield the highest revenue for your firm if the other firm produced 90. In the table, there were two correct answers: 120 and 150. However, in the experiment itself it will also be possible to pick any integer quantity between 120 and 150. What production level will yield the highest end income for your firm if you are allowed to pick any integer production level? Tip: use the calculator!

\section{End of Instructions}

You are now ready to start the experiment. By clicking on the next link, you will go to the experiment as soon as everyone has finished reading the instructions. In this part of the experiment, there will be no time to practice: you will immediately go on to the part where your earnings will be paid out. In total, there will be 3 rounds. In every round you will be matched with a different firm. Because there are no practice rounds, the timer will be set 
to 1 minute and 40 seconds per period in the first round and to 40 seconds per period in later rounds. Thus, you will have slightly more time in the first round to make a decision. If you fail to make your decision in time, you will automatically produce zero and move on to the next period. The timer is reset in every period, regardless of how much time you had left after the preceding period. Finally, note that in many cases only a small fraction of the required time might be needed to make a decision.

\section{Instructions Part III}

We will now start with the third and final part of this experiment. In many ways, this part will be a mix between part I and part II. In particular, you will still be the manager of a firm. Moreover, in this part you will have to deal with one other firm, like in part II. At the same time, you will only have a limited stock of resources available for production, like in part I. Finally, fixed costs will be slightly different from either of these parts. These changes will be explained in greater detail below and on the next page.

Firstly, as in part I you will have only a limited stock of resources available for production. To be more precise, you will have a total resource stock of 480 in every round. As in part I, you do not have to use up all your resources. Likewise, it is not necessary to produce in every single period. At the same time, it is also very well possible to use up your whole resource stock and produce in all periods. At the start of each new round, your resource stock will be replenished, as before. In total, this part of the experiment will consist of 10 rounds.

Moreover, there is one other active firm on the market, like in part II. Once again the other firm you face will be the same in every period of the same round but will change in each new round. You will not know with whom you will be matched, like others will not know with whom they will be matched. Anonymity is ensured.

As a result of these changes, the effect of your quantity on market price has changed. Like in part II, a one unit increase in production by either you or the other firm will lower the market price by 1 . However, the resulting prices are slighly different; in particular, prices are now between 0 and 372. The calculator has been updated to take this into account. 


\section{Expectations and Earnings}

The payment mechanism in this part of the experiment is almost identical to the mechanism used in the first two parts. Your payment after each round is still determined using the following formula:

\section{Payment $=$ Total End Income - Fixed Cost}

Your payment will be converted into euros at a rate of 10000 points per euro, such that 1000 points are worth 0,10 euros. Moreover, the interest rate will still be equal to $10 \%$. The only difference is that fixed costs will be equal to 113000 .

There is one new thing about this part of the experiment though. In every even round $(2,4$, etc. $)$, you are also asked to predict the production of the other firm. It will also be made clear before the start of the round whether or not you have to make predictions during that round and it will also be clear from the decision screen. During rounds where predictions are asked you will have slightly more time to make your decision. Other than that, the decision screen will be very similar to the previous parts of the experiment.

At the end of the experiment, we will randomly pick one prediction you made during the experiment and pay you an additional amount of money based on its accuracy. For a perfect prediction, you will earn 5 euros. If you make an error you will earn 5 euros minus the error times 20 cents. Thus, if you make an error of 25 , you will earn 0 (and if you make a bigger error you will still earn 0). Take predictions seriously, since they will earn you extra money at the end of the experiment. Before going to the experiment, we would like to ask you one more check-up question.

\section{End of Instructions}

You are now ready to start the experiment. By clicking on the next link, you will go to the experiment as soon as everyone has finished reading the instructions. In this part of the experiment, there will be no time to practice: you will immediately go on to the paid-out part. In total, there will be 10 rounds. In every round you will be matched with a different firm. Because there are no practice rounds, the timer will be set to 1 minute and 40 seconds 


\section{Your Decision in Period 3 out of 6 (Round 2 out of 10) \\ So far you have earned 52902 points. \\ You still have 300 units of resource remaining.}

How much do you want to produce this period: $\square$ (Integer between 0 and 186)
How much do you expect the other to produce this period:

This Round's History:

\begin{tabular}{|l|l|l|l|l|l|l|}
\hline \multicolumn{1}{|c|}{ Period } & Own & Other & Expected Other & Price & Revenue & End Income \\
\hline 2 & 88 & 85 & 90 & 199 & 17512 & 25639 \\
\hline 1 & 92 & 96 & 91 & 184 & 16928 & 27263 \\
\hline Remaining & 300 & 299 & - & - & Totals & $\mathbf{5 2 9 0 2}$ \\
\hline
\end{tabular}

Figure 9: Decision Screen

per period in the first round and to 40 seconds per period in later rounds. When you have to make a prediction, the time will be increased by 20 seconds. Thus, you will have slightly more time in the first round and in prediction rounds. If you fail to make your decision in time, you will automatically produce zero and move on to the next period. The timer is reset in every period, regardless of how much time you had left after the preceeding period. Finally, note that in many cases only a small fraction of the required time might be needed to make a decision.

\section{References}

Abbink, K. and J. Brandts. 2008. "Pricing in Bertrand competition with Increasing Marginal Costs." Games and Economic Behavior 63 (1):1-31.

2009. "Collusion in Growing and Shrinking Markets: Empirical Evidence from Experimental Duopolies;." In Experiments and Competition Policy, edited by J. Hinloopen and H.-T. Normann. Cambridge University Press, 34-60.

Adelman, M.A. 2002. "World Oil Production and Prices 1947-2000." The Quarterly Review 
of Economics and Finance 42:169-91.

Arrow, K. J. and S. Chang. 1978. "Optimal Pricing, Use and Exploration of Uncertain Natural Resource Stocks." Journal of Environmental Economics and Management 9 (1):1-10.

BP, British Petroleum. 2010. "British Petroleum Statistical Review 2010." Available from http://www.bp.com/ (accessed August 24th, 2010).

Brown, A.L., Z.E. Chua, and C.F. Camerer. 2009. "Learning and Visceral Temptation in Dynamic Savings Experiments." Quarterly Journal of Economics 124 (1):197-231.

Brown, M., C.J. Flinn, and A. Schotter. forthcoming. "Real-Time Search in the Laboratory and the Market." American Economic Review .

Bulletin, Energy. 2006. "Clinton: not briefed on peak oil." http://www.energybulletin.net/node/18138 (accessed December 14th, 2010).

Cairns, R.D. 1986. "More on Depletion in the Nickel Industry." Journal of Environmental Economics and Management 13:93-8.

Cairns, R.D. and G.A. Davis. 1998. "On Using Current Information to Value Hard-Rock Mineral Properties." The Review of Economics and Statistics 80 (4):123-40.

Cox, J. and J. Kennedy. 2005. "How Much More Rent Could Have Been Extracted From Nauru's Phosphate Deposits?" In MODSIM 2005 International Congress on Modelling and Simulation, edited by A. Zerger and R.M. Argent. Modelling and Simulation Society of Australia and New Zealand, 170-6.

Croson, R. 2000. "Thinking like a Game Theorist: Factors Affecting the Frequency of Equilibrium Play." Journal of Economic Behavior and Organization 41:299-314.

D'Alessio, M., A. Gurarion, V. De Pascalis, and P.G. Zimbardo. 2003. “Testing Zimbardo's Stanford Time Perspective Inventory (STPI) -Short Form: An Italian Study." Time and Society 12:333-47.

Deffeyes, K. S. 2005. Beyond Oil: The View from Hubbert's Peak. New York: Hill and Wang. 
Déry, P. and B. Anderson. 2007. "Peak Phosphorus." http://www.energybulletin.net/node/33164 (accessed December 14th, 2010).

Devarajan, S. and A.C. Fisher. 1981. "Hotelling's Economics of Exhaustible Resources: Fifty Years Later." Journal of Economic Literature 19 (1):65-73.

Engel, C. 2010. "How Much Collustion? A Meta-Analysis of Oligopoly Experiments." Journal of Competition Law and Economics 3 (4):491-549.

Ezzati, A. 1976. "Future OPEC Price and Production Strategies as Affected by its Capacity to Absorb Oil Revenues." European Economic Review 8 (2):107-138.

Farrow, S. 1985. "Testing the Efficiency of Extraction from a Stock Resource." Journal of Political Economy 93 (3):452-87.

Gächter, S. and E. Renner. 2010. "The Effects of (Incentivized) Belief Elicitation in Public Good Experiments." Experimental Economics 13 (3):364-77.

Gerlagh, R. and M. Liski. Forthcoming. "Strategic Resource Dependence." Journal of Economic Theory .

Gray, L.C. 1914. "Rent under the Assumption of Exhaustibility." Quarterly Journal of Economics 28:466-89.

Griffin, J.M. 1985. "OPEC Behavior: a Test of Alternative Hypotheses." American Economic Review 75 (5):954-63.

Groot, F., C. Withagen, and A. de Zeeuw. 2003. "Strong Time-Consistency in the Cartelversus-Fringe Model." Journal of Economic Dynamics and Control 28 (2):287-306.

Halvorsen, R. and T.R. Smith. 1991. "A Test of the Theory of Exhaustible Resources." The Quarterly Journal of Economics 106 (1):123-140.

Hamilton, J.L. 2009. "Understanding Crude Oil Prices." Energy Journal 30 (2):179-206.

Heaps, T. 1985. "The Taxation of Nonreplenishable Natural Resources Revisited." Journal of Environmental Economics and Management 12 (1):14-27. 
Heinberg, R. 2007. "Peak Coal: Sooner than you Think." http://www.energybulletin.net/29919.html (accessed December 15th, 2010).

Hotelling, H. 1931. "The Economics of Exhaustible Resources." Journal of Political Economy $39: 137-75$.

Huck, S., H.-T. Normann, and J. Oechssler. 1999. "Learning in Cournot Oligopoly an Experiment." Economic Journal 109:80-95.

. 2000. "Does Information about Competitors' Actions Increase or Decrease Competition in Experimental Oligopoly Markets?" International Journal of Industrial Organization $18: 39-57$.

Krautkraemer, J.A. 1998. "Nonrenewable Resource Scarcity." Journal of Economic Literature $36(4): 2065-107$.

Kronenberg, T. 2008. "Should We Worry About the Failure of the Hotelling Rule." Journal of Economic Surveys 22 (4):774-93.

Lewis, T. and R. Schmalensee. 1980. "On Oligopolistic Markets for Non-Renewable Natural Resources." Quarterly Journal of Economics 95 (3):475-91.

Livernois, J. 2009. "On the Empirical Significance of the Hotelling Rule." Review of Environmental Economics and Policy 3 (1):22-41.

Livernois, J. and P. Martin. 2001. "Price, Scarcity Rent and a Modified r per Cent Rule for Non-Renewable Resources." The Canadian Journal of Economics 34 (3):827-45.

Loury, G.C. 1986. "A Theory of 'Oil'igopoly: Cournot Equilibrium in Exhaustible Resource Markets with Fixed Supplies." International Economic Review 27 (2):285-301.

Mead, W.J. 1979. "The Performance of Government Energy Regulations." American Economic Review 69 (2):352-6.

Mouawad, J. 2008. "Oil hits \$ 104 as OPEC rebuffs Bush." 
http://www.nytimes.com/2008/03/05/business/worldbusiness/05cnd-opec.html (accessed January 18th, 2011).

Newbery, D.M. 1981. "Oil Prices, Cartels, and the Problem of Dynamic Consistency." Economic Journal 91:617-46.

Offerman, T., J. Potters, and J. Sonnemans. 2002. "Imitation and Belief Learning in an Oligopoly Experiment." Review of Economic Studies 69:973-97.

Pindyck, R.S. 1978. "The Optimal Exploration and Production of Nonrenewable Resources." Journal of Political Economy 86 (5):841-61.

. 1980. "Uncertainty and Exhaustible Resource Markets." Journal of Political Economy $88(6): 1203-25$.

—. 1981. "Models of Resource Markets and the Explanation of Resource Price Behavior." Energy Economics 3:130-9.

Polasky, S. 1992. "Do Oil Producers Act as 'Oil'igopolists?" Journal of Environmental Economics and Management 23 (3):216-47.

Slade, M.E. 1982. "Trends in Natural-Resource Commodity Prices: An Analysis of the Time Domain." Journal of Environmental Economics and Management 9 (2):122-37.

—. 1988. "Grade Selection under Uncertainty: Least-Cost Last and Other Anomalies." Journal of Environmental Economics and Management 15 (2):189-205.

Smith, G.O. 1920. "Where the World Gets Its Oil." The National Geographic Magazine 37 (2):181-202.

Smith, J.L. 2005. "Inscrutable OPEC? Behavioral Tests of the Cartel Hypothesis." The Energy Journal 26 (1):51-82.

Solow, R.M. 1974. "The Economics of Resources or the Resources of Economics." American Economic Review 64 (2):1-14. 
Teece, J. 1982. "A Behavioral Analysis of OPEC: An Economic and Political Synthesis." Journal of Business Administration 13:127-59.

Terrel, D. 1994. "A Test of the Gambler's Fallacy: Evidence from Pari-mutuel Games." Journal of Risk and Uncertainty 8 (3):309-17.

Veldhuizen, R. Van. 2009. Strategic Behavior on a Natural Resource Market: An Experiment. Master's thesis, Tinbergen Institute.

Williams, J.L. 2009. "Oil Price History and Analysis (Updating)." http://www.wtrg.com/prices.htm (accessed April 22nd, 2010).

Zwanenburg, M. 2010. "Europe's Energy Portal: Depletion." http://www.energy.eu/\#depletion (accessed December 2nd, 2010). 